ISSN: 0213-2079 - ISSN electrónico: 2386-3889

DOI: https://doi.org/10.14201/shhmo2018402305343

\title{
IDEAS DEL DUQUE DE BÉJAR PARA EL REAL SITIO DE ARANJUEZ EN 1580
}

\section{Ideas of the Duke of Béjar for the Royal Site of Aranjuez in 1580}

\author{
José MUÑOZ DOMÍNGUEZ \\ IES «Francisco Giner de los Ríos» (Segovia) \\ Correo-e: festinalente@hotmail.com
}

RESUMEN: La aportación de ideas para mejorar el Real Sitio de Aranjuez durante el reinado de Felipe II no se redujo exclusivamente al círculo de arquitectos e ingenieros que trabajaban para el rey, sino que contó con eventuales colaboraciones cortesanas, como las propuestas ofrecidas en la primavera de 1580 por Francisco de Zúñiga y Sotomayor, IV duque de Béjar, documentadas en una carta dirigida al secretario real Mateo Vázquez de Leca. La contribución del duque se refería principalmente a la ubicación de la Casa de los Oficios, a la dotación de un pasaje cubierto y descubierto y a la creación de un espacio ajardinado de transición entre los Oficios y el jardín privado del rey, ideas que se estudian dentro del contexto de las obras reales bajo la hipótesis de un cambio de proyecto para la Casa de los Oficios después de 1578, llevadas a cabo total o parcialmente desde 1584.

Palabras clave: Real Sitio de Aranjuez; jardines y Casa de los Oficios; Felipe II; Francisco de Zúñiga y Sotomayor, IV duque de Béjar; Mateo Vázquez de Leca.

ABSTRACT: The contribution of ideas to improve the Royal Site of Aranjuez during the reign of Philip II was not reduced only to the circle of architects and engineers who worked for the king, but had potential collaborations courtesans, as the proposals offered in the spring of 1580 by Francisco de Zúñiga y Sotomayor, IV Duke of Béjar, documented

Ediciones Universidad de Salamanca / @®®@ Stud. his., H. ${ }^{a}$ mod., 40, n. 2 (2018), pp. 305-343 
in a letter to the royal secretary Mateo Vázquez de Leca. The Duke's contribution was mainly concerned with the location of the Casa de los Oficios, to the provision of a covered and discovered walkway and the creation of a landscaped area of transition between the Oficios and the private garden of the king, ideas are studied in the context of real works (in some cases revised chronology) under the hypothesis that were considered in the project change to the Casa de los Oficios after 1578, conducted wholly or partly since 1584 .

Key words: Royal Site of Aranjuez; gardens and the Casa de los Oficios; Philip II; Francisco de Zúñiga y Sotomayor, IV Duke of Béjar; Mateo Vázquez de Leca.

\section{PRESENTACIÓN}

La intensa correspondencia entre Felipe II y sus arquitectos es asunto bien estudiado y, desde luego, fuente de primera mano para establecer la historia constructiva de casi todos los edificios y jardines que se crearon para el monarca durante aquel reinado. Mucho menos conocidas son las ideas que el rey intercambiaba con personas ajenas a la profesión de arquitecto acerca de los mismos edificios y sus entornos.

Dentro de ese círculo de allegados, algunos miembros importantes de la nobleza titulada y de los Grandes de España destacaban por su inclinación a la arquitectura, como el conde de Chinchón, el marqués de Velada o los miembros de la Academia de Letras, Matemáticas y Arquitectura que presidiera el III duque de Alba, y de la que formaban parte Juan de Idíaquez, Juan de Silva, Cristóbal de Moura, el conde de Olivares o Juan de Zúñiga, pariente de nuestro protagonista. Junto ellos se encontraba también el duque de Béjar, Francisco de Zúñiga y Sotomayor ${ }^{1}$, cuya afición al arte de construir puede demostrarse de palabra y obra. En el segundo caso por la actividad edilicia que emprendió a pesar de la penuria económica de su $\mathrm{Casa}^{2}$ y en el primero, por sus propias

1. Francisco de Zúñiga y Sotomayor fue el principal creador de la villa suburbana El Bosque de Béjar, a la que dedicamos nuestra tesis doctoral en curso bajo la dirección de Miguel Ángel Aníbarro Rodríguez, Departamento de Composición Arquitectónica, Escuela Técnica Superior de Arquitectura de Madrid (ETSAM), Universidad Politécnica de Madrid (UPM).

2. Acerca de las obras emprendidas por el duque de Béjar en la villa titular de sus estados, vid. Muñoz Domínguez, J.: «Francisco II, arquitecto remedón. Una aproximación biográfica al duque Francisco de Zúñiga y Sotomayor como entendido en arquitectura y comitente», en

Ediciones Universidad de Salamanca / 요 Stud. his., H. ${ }^{a}$ mod., 40, n. 2 (2018), pp. 305-343 
palabras dirigidas al rey en la carta del 3 de abril de 1580, que fue dada a conocer por Fernando Bouza ${ }^{3}$ en 1998 -aunque no transcrita ni publicada hasta la fecha en lo que concierne al Real Sitio de Aranjuez (figs. 1, 2 y 3)- y que será objeto de análisis a lo largo de estas páginas.

Se definía el duque en la misiva como remedón, es decir, aquel que se dedica a «seguir las mismas huellas y vestigios de otro, ó llevar el mismo méthodo, orden y disciplina» ${ }^{4}$, según acepción recogida en el Diccionario de Autoridades. Pero mientras Bouza interpreta que tal emulación tomaba su referente en el propio monarca, parece más probable que lo hiciera del arquitecto como figura de prestigio al expresar «los que somos remendones (sic) presumimos como si entendiesemos las cosas de la arquitetura $»^{5}$, para lanzarse acto seguido a opinar acerca de algunos aspectos que juzgaba poco convenientes en Aranjuez (observados tras su visita en marzo de 1580), y sobre los que aportaba propuestas de mejora.

¿Quién era este personaje que con tanta franqueza se permitía someter a crítica las obras reales? Aunque sin ocupar puestos relevantes de la Corte como sus contemporáneos el III duque de Alba o el I marqués de Santa Cruz, o como sus parientes Luis y Juan de Zúñiga y Requesens, o hasta su propio hermano Antonio de Zúñiga Guzmán y Sotomayor, gobernador de Milán, lo cierto es que el IV duque de Béjar pertenecía al reducido grupo de nobles con Grandeza de España de primera clase, siempre cercanos al monarca, y recibió importantes

Estudios Bejaranos, no 16, Béjar, 2012, pp. 19 a 38. Entre tales obras destaca la renovación del palacio ducal a cargo del maestro Pedro de Marquina y otros artífices (nuevo patio porticado, corredor hacia la Huerta del Aire, portada monumental frente a la Plaza Mayor, miradores con galerías sobre el antiguo adarve, etc.) y la prosecución o creación de las villas suburbanas de El Bosque y Los Picozos, todo ello realizado entre 1567 y 1585, poco antes de la quiebra económica de la Casa Ducal de Béjar.

3. Bouza Álvarez, F.: «Ardides del arte. Cultura de corte. Acción política y artes visuales en tiempos de Felipe II», en Checa Cremades, F. (coord.): Felipe II: un príncipe del Renacimiento. Un monarca y su época. Madrid, 1998, pp. 57 a 82 (p. 78), posteriormente retomado en «Realeza, aristocracia y mecenazgo (del ejercicio del poder modo calamo)», en Egido Martínez, A., y Laplana Gil, J. E. (eds.): Mecenazgo y Humanidades en tiempos de Lastanosa. Homenaje a la memoria de Domingo Ynduráin. Zaragoza, 2008, pp. 69 a 88 (p. 69). Recientemente se ha hecho eco de la misma carta Aguilar Perdomo, M. R.: «El palacio fuera de palacio: prácticas arquitectónicas y festivas en jardines históricos y literarios de la temprana Edad Moderna», en Anales de Historia del Arte, vol. 23, número especial (II), Madrid, 2013, pp. 415 a 429.

4. Diccionario de Autoridades, Real Academia Española de la Lengua, Madrid, 1737, voz remedar (consultado en su edición digital http://buscon.rae.es/ntlle).

5. Archivo del Instituto Valencia de Don Juan (AIVDJ), Duque de Béjar a Mateo Vázquez de Leca, Envío 7. T. II, 110, Madrid, 3 de abril de 1580. Se hace extensiva la referencia a todas las citas de este documento.

Ediciones Universidad de Salamanca / 요 Stud. his., H. ${ }^{a}$ mod., 40, n. 2 (2018), pp. 305-343 
encargos de confianza del rey, en algún caso con grave perjuicio para sus arcas, tan llenas en tiempos del segundo duque y tan exhaustas décadas después por exceso de dotes, pleitos y acreedores 6 .

Francisco de Zúñiga y Sotomayor, hijo de Teresa de Zúñiga -III duquesa de Béjar, fallecida en 1565- y de Francisco de Sotomayor -V conde de Belalcázar y duque consorte, fallecido en 1544-, nació en Sevilla hacia 1523 y apenas se tienen noticias de las etapas vitales anteriores al ducado, salvo el probable acompañamiento del príncipe Felipe en su boda con María de Portugal (Salamanca, 1543) y las capitulaciones matrimoniales entre Zúñigas y Mendozas para concertar su casamiento con Guiomar de Aragón -hija de Íñigo López de Mendoza, IV duque del Infantado- que se celebraría en 1545. Por entonces ostentaba el título de marqués de Ayamonte, muy pronto viudo -desde 1548- tras el segundo parto de su esposa. Este hecho personal debió de afectar al futuro duque lo bastante como para mantener un largo y discreto retiro del mundo cortesano ${ }^{7}$, interrumpido no obstante para incorporarse al acompañamiento del todavía príncipe en su viaje a Inglaterra en 1554, cuando la boda con María Tudor, y emprender retorno por territorios flamencos en un periplo de cinco años que, consecuencias políticas aparte, fue determinante en la actividad arquitectónica del recién coronado rey ${ }^{8}$ y que suponemos también lo sería para el marqués de Ayamonte.

En 1565, por fallecimiento de la duquesa madre (y anteriormente de su hermano mayor Alonso, en 1559), Francisco de Zúñiga heredó el mayorazgo de la Casa de Béjar como IV duque, segundo del mismo nombre. $\mathrm{Al}$ año siguiente concertaba nuevo matrimonio con Brianda Sarmiento de la Cerda Pimentel, hija de los duques de Híjar y condes de Salinas, y poco después, a principios de 1570, recibía de Felipe II el encargo de acompañar desde Italia a la futura reina y cuarta esposa, Ana de Austria. El proceso, bien documentado a través de las

6. Sobre la situación económica de los duques de Béjar entre los siglos XV y XVII, vid. Rojo Vega, Anastasio: Documentos sobre los seis primeros duques de Béjar. Valladolid, 2008, pp. 15 y ss. El autor ofrece una copiosa base documental que permite constatar el progresivo endeudamiento de la Casa desde las campañas de guerra costeadas por el duque Francisco I a favor del emperador y los numerosos pleitos posteriores.

7. Majada Neila, José Luis: «La ' $G$ ' de Guiomar», en Domínguez Garrido, U., y Muñoz Domínguez, J. (coords.): El Bosque de Béjar y las Villas de Recreo en el Renacimiento, Béjar, 1997, pp. 123 a 134.

8. Entre otros, vid. Barbeito Díez, J. M.: «Felipe II y la arquitectura. Los años de juventud», en Checa Cremades, Felipe II: un principe del Renacimiento..., pp. 83 a 103, y Barbeito Díez, J. M., y Ortega Vidal, J.: «Los artífices de las obras reales», en Añón Feliú, C., y Sancho Gaspar, J. L. (eds.): Jardin y Naturaleza en el Reinado de Felipe II, Aranjuez, 1998, pp. 245 a 273.

Ediciones Universidad de Salamanca / ف®@ Stud. his., H. ${ }^{a}$ mod., 40, n. 2 (2018), pp. 305-343 
decenas de cartas que se conservan, se prolongó durante meses hasta que en marzo de 1570 se renunciaba a la «jornada de Génova» para trasladar por tierra hasta los puertos de Flandes a Ana de Austria y recibirla en el de Santander. Francisco II y su pariente, el cardenal y arzobispo de Sevilla Gaspar de Zúñiga y Avellaneda, desplegaron el costoso acompañamiento nupcial en varias etapas desde Cantabria hasta Segovia, donde se celebró la boda entre grandes fastos el 14 de noviembre. Poco después, en 1572, el duque volvía a ocupar lugar preferente en el complejo protocolo ${ }^{9}$ de la Corte al sostener en brazos al infante don Fernando durante la ceremonia del bautizo real, el mismo rango que tuvo su antepasado y segundo duque de Béjar cuando hizo lo propio en el bautizo del príncipe Felipe en 1527. Francisco de Zúñiga participó en otras ceremonias reales en 1580: el bautizo de la infanta doña María en el mes de febrero y el juramento del príncipe don Diego el 14 de marzo, fecha cercana a su visita al conjunto de Aranjuez.

No fueron estas las únicas comparecencias y misiones requeridas por el monarca: también hubo de ocuparse el duque de su parte alícuota en la defensa del reino frente al enemigo africano o portugués (dada la proximidad a la costa y a la raya del marquesado de Gibraleón, uno de sus estados andaluces ${ }^{10}$ ), concretada en diversas campañas que se documentan entre 1578 y 1591. En ese último año consta su presencia en El Escorial por invitación de Felipe II para pasar allí la Semana Santa y para contar con su asistencia, cinco meses después, en la ceremonia de entrega del «Estoque, y el Pileo ò Capelo» ${ }^{11}$ al heredero de la Corona, el futuro Felipe III. Pocas semanas más tarde, el duque partió hacia Ávila y allí le sorprendió la muerte el día 20 de septiembre ${ }^{12}$.

Mayor interés que estos acompañamientos, ceremonias y requerimientos bélicos reviste para nosotros el vínculo con el monarca en asuntos de arquitectura,

9. Desde la implantación definitiva de la etiqueta de la Casa de Borgoña en 1548, el lugar ocupado por cada cortesano o servidor real estaba prefijado y revestía un carácter simbólico, estrechamente vinculado a su posición social.

10. Con no pocas reticencias por parte de la alta nobleza implicada, según se deduce del pleito entablado después de 1596 por la Corona, pero sobre hechos ocurridos en 1584 y años posteriores (el documento en AHN, Nobleza, Osuna, C. 382, D. 58).

11. Anónimo: Le Ceremonial de la Cour d'Espagne, Livre I, qui contient l'etiquete de la Cour, transcrito de un original en castellano conservado en la Biblioteca de El Escorial y publicado en Barbeyrac, Jean: Supplément au corps universel diplomatique du droit des gens, avec le cérémonial diplomatique des cours de l'Europe, mis en ordre et considérablement angmenté par Jean Barbeyrac, vol. 5, 1739, p. 191.

12. El pésame de Felipe II por la muerte del duque se conserva en una carta dirigida a Francisco Diego López de Zúñiga, su primogénito y heredero del ducado (en AHN, Nobleza, Osuna, C. 3620, D. 6). 
algo de lo que sólo conocemos dos testimonios que probablemente no sean únicos. De hecho, la carta que seguidamente analizamos permite comprender mejor el motivo por el que Felipe II quiso mostrar la obra de El Escorial a Juan Andrea Doria y al duque de Béjar aquella Semana Santa de 1591. El cronista Fray Jerónimo de Sepúlveda narraba cómo el rey había enviado

a esta Casa a que tuviesen la Semana Santa y Pascua al príncipe Andrea Doria [...] y al Duque de Béjar, en su nombre, y que lo mirasen todo y después se lo avisasen qué les habia parecido ${ }^{13}$

Con el resultado, seguramente previsto por Felipe II y ya comentado por Checa Cremades y Sáenz de Miera, de un previsible estupor en ambos invitados, pues

Fueron espantados [estos] príncipes de ver esta Casa [en] lo material y espiritual; y como nunca lo bubiesen visto causó en ellos grande admiración y no bartaban de espantar de ver lo uno y lo otro. El edificio y su ornato los espantaba, lo divino los elevaba, y ansí no salian de sí ni [sabían] qué decirse ${ }^{14}$.

El rey no perdía ocasión de mostrar la obra inmensa de El Escorial a cuantos pudieran acercarse hasta aquellas soledades en su tránsito por la Corte, ya fueran embajadores japoneses o diplomáticos de las cortes europeas; también a personas de confianza como Doria, «llamado de su Rey a tratar cosas de mucha importancia» ${ }^{15}$, según el mismo Sepúlveda. En cambio, la invitación dirigida al duque de Béjar no parece ir asociada a cuestión de Estado o negocio particular alguno, ni tener más objetivo que conocer su opinión sobre la obra.

La cita del cronista no proporciona más detalles, de modo que las verdaderas razones del rey se nos escapan. Pudiera tratarse de mero orgullo exhibicionista, puro ejercicio del poder o, más probablemente, estrategia publicitadora de la dinastía, pero también de una sincera voluntad por recabar el parecer de alguien

13. Sepúlveda, Fray Jerónimo de: Historia de varios sucesos y de las cosas notables que han acaecido en España y otras naciones desde el año de 1584 hasta el de 1603. Escrita por el P. Fray Jerónimo de Sepúlveda, el Tuerto, monje jerónimo de San Lorenzo el Real de el Escorial, en Zarco Cuevas, J.: Documentos para la historia del monasterio de San Lorenzo el Real de El Escorial. Tomo IV, Madrid, 1924 (citado por Sáenz de Miera, Jesús: «La magnificencia del Rey Prudente y la fama de El Escorial», en Checa Cremades: Felipe II: un príncipe del Renacimiento..., pp. 105 a 134, p. 113). En el texto aparece el nombre de Andrea Doria, fallecido en 1560; obviamente se trataba de su hijo, Juan Andrea Doria, príncipe de Melfi.

14. Ibidem.

15. Ibidem. Sáenz de Miera, en Op. cit., interpreta este tipo de visitas, en algún caso minuciosamente programada por el rey, como clara estrategia de publicitación de su persona y, sobre todo, de la monarquía hispánica. 
-uno de sus «primos» ${ }^{16}$ - con quien compartía el gusto por la arquitectura. De ser este el motivo, la relación contaba con antecedentes once años atrás.

\section{EL TEXTO. CARTA DEL DUQUE DE BÉJAR A MATEO VÁZQUEZ, 3 DE ABRIL DE 1580}

Pasada la Pascua de aquel año, Francisco de Zúñiga había estado de visita en Aranjuez, donde, a lo que parece, no dejó de observarlo todo con verdadero espíritu crítico y de tratar con los responsables de la obra, a quienes dio su opinión fundada "y paresioles serlo» ${ }^{17}$, según exponía en su carta del 3 de abril, dirigida al rey a través del secretario Mateo Vázquez de Leca, en la que informaba de la misma «razon» o parecer sobre ciertas partes poco convenientes a «aquella maquina».

Antes de tratar de tales edificios y de su entorno, el duque se refería a otros asuntos de Estado y personales -que no vienen al caso- empleando un estilo abstruso, protocolario y de escasa capacidad comunicativa, propio de quien no tiene nada importante que decir y por ello recurre a evasivas, vaguedades o socorridos formulismos. En la parte que concierne a las obras de Aranjuez sucede todo lo contrario: Francisco de Zúñiga se suelta en un discurso directo y sincero con la determinación de quien comunica algo del mayor interés, aunque sin dejar de utilizar conocidos artificios expositivos como la captatio benevolentiae en forma de falsa modestia («los que somos remendones presumimos como si entendiesemos las cosas de la arquitetura»), la lisonja hacia el monarca, el manifiesto deseo de «aber en algo acertado para que el gusto de su Majestad no fuese menos» y la disculpa final por el tiempo sustraído a alguien con tantas ocupaciones. El tono llega a ser desenfadado (divertido, según Bouza), lo que presupone confianza con su destinatario, y no faltan formas dialectales propias del castellano de Sevilla -pequeña patria del duque remedón y adoptiva del secretario Vázquez- que redundan en el mismo trato afable.

En cuanto a la crítica, se centraba en la incómoda presencia de las «Casas de los Serviçios» ${ }^{18}$ (las Casas de Oficios) situadas frente a la casa del rey, es

16. El tratamiento de primo quedaba reservado a determinadas personas en función de su rango y no de su parentesco con el rey, documentado para el caso del duque de Béjar en la correspondencia generada por la cuarta boda del monarca en 1570.

17. Todas las citas se referirán al documento referenciado en nota 4 (AIVDJ, Envío 7, T II, 110).

18. En las anotaciones escritas por Mateo Vázquez en un folio adicional a la misma carta, queda aclarado que tales «Casas de los Seviçios» coinciden con la «Casa de los Oficios». En la documentación sobre Aranjuez aparecen ambas denominaciones de forma habitual.

Ediciones Universidad de Salamanca / 요 Stud. his., H. ${ }^{a}$ mod., 40, n. 2 (2018), pp. 305-343 
decir, al «Quarto Real» o Cuarto Nuevo que se construía bajo la dirección de Juan de Herrera, única parte del palacio que se pudo completar en vida del monarca. Más adelante se refiere también a la Capilla Real adyacente, situada en la misma zona sur.

\section{Al duque le parecía}

inconviniente el camino que pasa junto a la galeria del jardin y estar allí a la vista desta galeria la Casa de los Servicios y que aquel quarto por aquella parte no dexava de ofender a la vista estar la casa delante

Cifraba tal ofensa en los enojosos comentarios y molestias que pudieran incomodar al rey, pues "parese inconveniente el ruido y cosas que de fuersa estando tan cerca la casa a de ser juez dellas su Majestad y algunos ratos cansalle».

Lo que el duque denomina «galería» consistía en un ándito elevado y muy estrecho que cerraba el jardín por el sur (no se había adosado aún la galería porticada) y que ofrecía otras incomodidades al carecer de comunicación con el suelo en su largo recorrido: «y en la galeria que va haciendo pared al jardín que corre alrededor de la casa parese que yendo su Majestad por ella no tiene salida sin volver por donde ha ido».

Pero el duque no se limitaba a poner en evidencia los inconvenientes, sino que aportaba propuestas para darles solución. Bastaba, por ejemplo, con apartar un tanto la Casa de los Oficios, ensanchando lo que entonces era un camino de acceso entre la «galería» y la zona de servicio, y transformar el terreno resultante en amplio prado limitado por arboledas; es decir, crear un área de transición resuelta como espacio cerrado y apartado, aunque concebido como obra de jardinería:

$y$ con hazerse alli entre la galeria y la casa ${ }^{19}$ un prado que corriese alrededor de toda esta galería y dando vuelta al rio guardando la proporsion y este prado con su espaldar y algunas fuentes que acompañasen y detras del espaldar arboledas que biziesen la vista con mas compostura y gusto

19. No cabe interpretar aquí que se trate de la casa real, sino la de los servicios, puesto que en un párrafo anterior indicaba la existencia del jardín, lo que haría innecesaria la introducción de un prado en su lugar; por tanto, el prado y demás acompañamiento jardinero han de entenderse al exterior, es decir, entre la «galería» del jardín y la Casa de los Oficios por el sur y su prolongación hacia el este. 
Pero la obra de los Oficios ya se había iniciado un par de años antes ${ }^{20}$ sobre una traza de Juan de Herrera de 1577, de modo que la propuesta implicaba un sobrecoste en derribos y obra nueva. Por ello propone, puesto que «ai tienpo ahora de que la Casa del Serviçio como abia de llegarse a la de su Majestad se haga la fabrica en el llano hazia la otra parte y no deshacer nada de lo hecho».

El alejamiento de la Casa de los Oficios suponía mejoras evidentes en las funciones de recreo y retiro a las que se destinaban palacio, galerías y jardines, pero perjudicaba las de tipo pragmático en cuanto al trato con la servidumbre y el diario avituallamiento. Para evitar nuevas incomodidades en ese aspecto, el duque propuso construir un pasadizo o galería alta y baja, sospechosamente parecida a la que se hizo a partir de 1584 y aún perdura tras las reformas de 1756:

desde la Casa del Servisio a la puerta que esta ordenada para la entrada del servisio una galeria baxa para que en tiempo de agua venga la vianda con mas acomodo [...] y por lo alto otra galeria descubierta para si acaso su Majestad alguna vez quisiese pasar a la Casa del Servicio fuese aquel el paso y no dexaria de adornar

Resuelto ese inconveniente, quedaba vía libre para establecer el prado con sus espaldares, fuentes y arboledas entre la Casa de los Oficios y la galería del jardín, «y el camino echalle por detrás de la casa de los serviçios».

La galería que cierra el jardín inmediato al palacio recuerda al ándito elevado de Valsaín o al anterior de Cadalso de los Vidrios (fig. 4), concebido como paseadero hacia el Jardín del Rey a la vez que hacia el paisaje, pero en el estado en el que la vio el duque en 1580 -sin el pórtico inferior adosado y, por tanto, muy angosta- obligaba a desandar lo paseado al regresar a la casa. Con el fin de evitar tal inconveniente, el duque ofrecía una solución válida para comunicar lo alto con lo bajo y el jardín privado con el prado exterior:

y jusgue que con hazerse tres cubos pegados a la galería por la parte de afuera al prado que dixe arriba y estos cubos guardaren en ellos la fabrica como esta todo lo demas y sirvan de escaleras con puertas en lo baxo asi para el jardin como para el prado

Los tres cubos o torres quedaban perfectamente situados en la propuesta, hasta el punto de que permiten localizar cada parte en los planos históricos conservados, como se verá más adelante:

20. Martín González, J. J.: «El Palacio de Aranjuez en el siglo XVI», en Archivo Español de Arte, t. XXXV, n 137, Madrid, 1962, pp. 237 a 252 (p. 246), a partir de documentación del Archivo General de Simancas (AGS), Aranjuez, leg. 7, fol. 26.

Ediciones Universidad de Salamanca / 요 Stud. his., H. ${ }^{a}$ mod., 40, n. 2 (2018), pp. 305-343 
y el uno donde junta la galeria con la torre de la capilla y el otro a la esquina que la haze al un paño y al otro y el otro al remate de la galeria y para este remate no creo seria herrado hazer una torre no mas alta que la galería que fuese paradero della

Esta última torre se alzaba sobre el ramal del Tajo desviado en la presa del molino y permitía la contemplación del paisaje humanizado y del entorno natural, pues «la vista y sitio era galanisima y apazible sobre el rio y jardines y aquellos canpos y alamedas».

No olvidaba el duque las funciones simbólicas del lugar y en concreto los frecuentes servicios religiosos, por lo que también sugería mejoras en la Capilla Real para adaptarla fácilmente a la modalidad misa de campaña:

y las quatro puertas de la capilla que salen al canpo demas de sus puertas de madera hazelles otras de rexa para en ocasiones que se ofresen de aver mucha jente este la capilla desenbarasada y puedan desde fuera oir misa

Como buen diletante o imitador de arquitecto, concluía su informe dejando constancia de su leal saber y entender, y de paso también la vaga referencia a un posible croquis de su mano (un «rasguño» como los que a veces trazaba el monarca) que habría acompañado a la carta: «He dicho mi razon; si lo fuere no esta perdido el rasguño y a no sello, echallo en la baraja ${ }^{21}$ como otras muchas cosas inpertinentes».

En el folio adicional del documento escribía el secretario Vázquez unas anotaciones sobre su contenido para facilitar la tarea al rey (fig. 3). Es muy significativo que las propuestas del duque hayan sido trasladadas en su integridad y tomadas casi literalmente por el secretario -verdadero filtro entre Felipe II y los allegados a la Corte- en el período de mayor poder político y de influencia sobre el monarca ${ }^{22}$.

21. La expresión viene recogida en Covarrubias y Orozco, S.: Tesoro de la Lengua Castellana o española, Madrid, 1611, como «Echarse uno en baraja es desistir de su pretensión, como haze el que en el juego no tiene puntos para poder querer el embite», y se incluye en el Diccionario de Autoridades de 1726 junto con otra más precisa: «Entrarse o echarse en la baraja. Metaphoricamente es desistir de la pretensión o intento que uno había emprendido, ú deseaba emprender».

22. El intrigante Mateo Vázquez de Leca, de origen sardo y educación sevillana, protegido del canónigo Diego Vázquez de Alderete y del cardenal Espinosa hasta obtener el favor real en 1573, contribuyó a la caída, seis años después, del secretario Antonio Pérez y la princesa de Éboli, partidarios del bando político opuesto al suyo. Esta situación dejaba a Vázquez en el mejor momento de su carrera, particularmente entre 1580 y 1585. Vid. Martínez Millán, J., y De Carlos Morales, C. J. (dir.): Felipe II (1527-1597). La configuración de la Monarquia hispana. Valladolid, 1998, pp. 500 a 502. 


\section{INTERPRETACIÓN DE LAS PROPUESTAS DEL DUQUE EN EL CONTEXTO DE LAS OBRAS}

Gracias a ciertos detalles de la carta es posible identificar los puntos sobre los que Francisco de Zúñiga propuso intervenir y también aventurar algunas precisiones sobre la cronología de la Casa de los Oficios en sus diferentes fases de proyecto y ejecución.

En el momento de su visita en marzo de 1580, el duque pudo dedicarse a inspeccionar un palacio incompleto (aproximadamente el ala sur o Cuarto del Rey, incluyendo la parte en ángulo de la Capilla Real), ya flanqueado por un muro con ándito superior frente a la fachada de solana, cercando el jardín privado resultante de estos tres límites más el murete oriental que lo cerraría por el cuarto. También debía ser reconocible una mínima parte de la obra de la Casa de los Oficios, motivo principal de crítica.

Desde luego, la documentación disponible confirma la existencia de tales edificaciones y su historia constructiva ha sido ya determinada por diversos autores $^{23}$ : la obra del palacio comenzó a levantarse en 1561 a partir de un proyecto de Juan Bautista de Toledo del año anterior (reformado en 1563) y, tras su muerte en 1567, proseguida bajo la dirección de Jerónimo Gili (entre 1567 y 1575) y de Juan de Herrera (entre 1575 y 1586); en 1577, el mismo arquitecto iniciaba las obras del Jardín del Rey, no concluidas hasta 1582, cuando se pudo instalar la fuente labrada por Roque Solario; la inmediata Capilla Real, con la torre que se eleva sobre ella, había sido terminada en 1576; la apertura de cimientos ${ }^{24}$ para la Casa de los Oficios data de 1578 (con proyecto de Juan de Herrera de 1577, aunque catorce años antes ya consta un proyecto de Juan Bautista de Toledo $^{25}$ ) y la galería sur, a modo de ándito o paseadero (todavía sin

23. Para el conjunto del Real Sitio seguimos preferentemente las obras de Álvarez de Quindós y Baena, J. A.: Descripción histórica del Real Bosque y Casa de Aranjuez. Madrid, 1804 (manejamos la edición original, aunque existe facsímil de 1993); Íñiguez Almech, F.: Casas Reales y Jardines de Felipe II. Roma, 1952; Martín González: «El Palacio de Aranjuez...»; Sancho Gaspar, J. L.: La Arquitectura de los Sitios Reales. Catálogo Histórico de los Palacios, Jardines y Patronatos Reales del patrimonio Nacional. Madrid, 1995; Luengo Añón, A.: Aranjuez, utopía y realidad. La construcción de un paisaje. Madrid, 2008; y Sanz Hernando, A.: El jardín clásico madrileño y los Reales Sitios. Madrid, 2009. Acerca de la Casa de los Oficios seguimos a Verdú Ruiz, M.: «Casa de Oficios y Casa de Infantes», en Riada: Estudios sobre Aranjuez, I. Plaza de San Antonio: Arte, Historia, Ciudad, Aranjuez, 1989, pp. 51 a 73; y Muñoz Garcinuño, G.: «La Casa de Oficios de Aranjuez», en Cuadernos de Arte e Iconografía, t. 12, n² 23, Madrid, 2003, pp. 77 a 256.

24. Así consta en Martín González: «El Palacio de Aranjuez...», pp. 237 a 252, y en Muñoz Garcinuño: «La Casa de Oficios...», pp. 77 a 256.

25. Como han señalado diversos autores, el lugar previsto para la Casa de los Oficios coincidía con la ubicación de uno de los estanques propuestos por Adrian van der Mulée y el rey

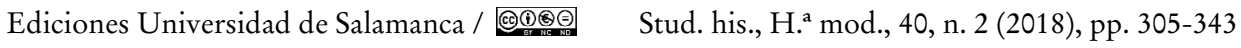


el pórtico exterior), no fue rematada hasta 1583 con sus barandillas de hierro y bolas de bronce ${ }^{26}$. Este conjunto de obras quedó representado por primera vez en el conocido dibujo de Jehan l'Hermite ${ }^{27}$, trazado durante su visita a Aranjuez en torno a 1588 a partir de lo que pudo observar (fig. 5), pero también ayudado de un plano que vio in situ y que posiblemente coincida con el de las Huertas de Picotajo, atribuido a Juan Bautista de Toledo o a Juan de Herrera, fechado entre 1560 y 1584 según diferentes autores ${ }^{28}$, y para el que proponemos acortar el intervalo entre 1577 a 1578 después de considerar el contenido de la carta del duque de Béjar.

Más dificultades ofrecen las estructuras de fábrica que se dan por ejecutadas en la carta, pero de las que no consta documentalmente que se hubieran realizado antes de marzo de 1580. Es posible que el duque se refiera indistintamente a unas y a otras por considerarlas como partes de un mismo proyecto al que habría tenido acceso a través de «los ministros de su Majestad» con quienes trató en su visita, incluso contando con las correspondientes trazas como guía. En tal caso, probablemente le fue mostrado el mismo plano general que vio l'Hermite unos ocho años después y que bien pudiera coincidir con el mencionado de

desestimó la idea del flamenco, según se comprueba en Archivo General de Simancas (AGS), Casas y Sitios Reales, Leg. 252, fol. 281563, Aranjuez, 5 de noviembre de 1563. En cuanto al proyecto de Herrera, consta el encargo de traza y condiciones en la declaración de Martín de Gaztelu, fechada en 27 de julio de 1577 (AGS, Aranjuez, leg. 7, fol. 26).

26. Luengo Añón: Aranjuez..., p. 131 y notas 426 a 428, a partir de documentación de AGS y AGP.

27. L'Hermite, J.: Vista de Aranjuez, 1586-1587, Biblioteca Real Alberto I, Bruselas. Este y otros dibujos sirven de ilustración a las memorias del mismo autor flamenco, tituladas Le passetemps y referidas a su estancia en España entre 1587 y 1598 en las que se incluye la descripción del Real Sitio (Biblioteca Real de Bruselas, Manuscrito II, 1028, escrito en 1602; edición española de Jesús Sáez de Miera, Aranjuez, 2005). l’Hermite llegó a España en 1587 y no entró al servicio del rey hasta pasado el invierno de ese año, por lo que su visita a Aranjuez probablemente no tuvo lugar hasta la primavera de 1588, fecha que proponemos como datación más temprana de su dibujo.

28. La fecha más antigua la propone Luengo Añón: Aranjuez, utopía y realidad..., pp. 78 a 80 , defendiendo la autoría de Juan Bautista de Toledo, y la más tardía es de Sancho Gaspar: La Arquitectura de los Sitios Reales..., p. 283 (aunque en p. 295 fecha el plano en 1581), quien se inclina por la autoría de Herrera o su taller entre 1580 y 1581, como la gran mayoría de autores (Cervera Vera, Rivera Blanco, Wilkinson Zerner, Merlos Romero), frente a Ortega Vidal (que lo relaciona con el proyecto original de Juan Bautista de Toledo), Íñiguez Almech, (que lo atribuye a Herrera, pero en 1572) o García Tapia (que lo considera posterior a 1581 y no realizado por Herrera, sino por alguno de los ingenieros o jardineros del Real Sitio). El documento se encuentra en el Archivo General de Palacio (AGP), Plano de las Huertas de Picotajo, con el Palacio Real y la Casa de Oficios, Biblioteca del Palacio Real, dib. IX-M-242, fasc. 2 (3-4), ca. 1580-1581 (aunque consideramos más probable ca. 1577-1578), y ha servido de base para nuestra hipótesis gráfica.

Ediciones Universidad de Salamanca / అ@@ Stud. his., H. ${ }^{a}$ mod., 40, n. 2 (2018), pp. 305-343 
las Huertas de Picotajo, en el que se aprecian de forma esquemática, pero con suficiente detalle, los edificios del palacio y la Casa de los Oficios en estado de proyecto (fig. 6).

La mayor diferencia entre lo construido hasta entonces y lo que puede deducirse de la carta es el estado de la galería, carente de pórtico exterior en el plano de conjunto (aunque visible en la versión reformada ${ }^{29}$ que hizo Juan Gómez de Mora en 1636, basada en otro plano anterior trazado por Herrera, no conservado) y que en 1580 se reducía a un ándito sobre el grueso del muro de cierre que apenas rebasaba la longitud del Jardín del Rey, según se aprecia en dos representaciones anónimas conservadas (fig. 7, Vista del Real Sitio de Aranjuez ${ }^{30}$, Museo del Prado, fechada en torno a 1630 -aunque probablemente sea anterior a 1613-, y fig. 8, Vista ideal del Palacio de Aranjuez, Patrimonio Nacional, Palacio de El Escorial, de la primera mitad del siglo XVII). Y sin embargo, el duque se refiere con toda claridad a dos tramos de galería dispuestos en ángulo hacia el río: «la galeria que va haciendo pared al jardín que corre alrededor de la casa» o «la esquina que la haze al un paño y al otro» con remate frente al Tajo. Puesto que ese segundo tramo con dirección norte-sur y parte del primero (en inmediata escuadra con él) no han podido ser documentados entonces y ni siquiera se aprecian en el dibujo de l'Hermite ni en otras representaciones posteriores (de hecho, no fueron construidos hasta 1727), sólo cabe entender que la crítica y propuesta del duque de Béjar se hizo sobre plano en lo que a esta galería se refiere, anticipándose a un previsible resultado que consideraba mejorable.

Otra de las incógnitas planteadas por la carta es el estado coetáneo de la Casa de los Oficios. Las nóminas de pago a los maestros, oficiales y peones con los que se ajustó la obra entre 1578 y 1580, publicadas por Muñoz Garcinuño ${ }^{31}$, aportan datos sobre el avance de los trabajos en su primera fase, que correspondía

29. Biblioteca Nacional de España (BNE), Planta baja de la Real Casa de Aranjuez, DIB/14/17/1, 1636, pórtico que no aparece representado en las trazas del mismo autor conservadas en la Biblioteca Vaticana, de 1626.

30. Anónimo: Vista del Real Sitio de Aranjuez, Museo Nacional del Prado, no de catálogo P07090, ca. 1636. Frente a la datación del Museo, la mayor parte de los autores aceptan la de 1630, aunque la ausencia del mirador de celosía que se instaló en 1616 sobre los dos tramos iniciales de la galería porticada (junto a la Capilla), renovado por otro de fábrica en 1744 (según Álvarez de Quindós: Descripción..., p. 201), permite una datación más antigua, probablemente anterior a la intervención de Juan Gómez de Mora en la Casa de los Oficios en 1613, cuando la obra de solar los terrados habría avanzado «hasta las quatro puertas quadradas» (Álvarez de Quindós: Descripción..., p. 221, en referencia a las puertas adinteladas de los pórticos este y oeste).

31. Muñoz Garcinuño: «La Casa de Oficios...», Apéndice documental, documentos 2 a 9, pp. 1 a 156. La mayor parte de nuestras citas de fuentes primarias proceden de este trabajo.

Ediciones Universidad de Salamanca / 요 Stud. his., H. ${ }^{a}$ mod., 40, n. 2 (2018), pp. 305-343 
a los cimientos, al zócalo de cantería y mampostería y a las primeras hiladas de ladrillo: serían esas partes construidas las que el duque menciona al sugerir «no deshacer nada de lo hecho de la Casa del Servisio». La cuestión pendiente es determinar qué parte había sido iniciada y en qué grado de reversibilidad se encontraba como para hacer factible la propuesta sin comprometer lo realizado.

El plano general con las Huertas de Picotajo probablemente sea el documento más temprano (por no decir el único) que permite conocer el primer proyecto de Juan de Herrera para la Casa de los Oficios, pues coincide en buena medida con los datos conocidos sobre la cimentación del edificio y no con los de su posterior alzado por partidas a destajo. La Memoria ${ }^{32}$ redactada por el propio Herrera para esa obra, fechada por Álvarez de Quindós en 1584, permite imaginar un edificio con características similares tanto en su localización aproximada al sur del palacio, con un «pórtico» frente al muro meridional del jardín, como en ciertos detalles compositivos: la presencia de "patinejos» (tres en el plano), de un "patio grande» y de un «tránsito descubierto que sirve para entrar a descargar [...] las acémilas» ${ }^{33}$. Es importante destacar que ni en el plano ni en la Memoria se registran pórticos perimetrales exteriores (sólo el de la fachada principal) y tampoco aparece por ninguna parte el paso elevado de conexión entre el palacio y la Casa de los Oficios, a pesar de lo que afirman varios autores ${ }^{34}$, confundidos sin duda por el mal estado del plano, compuesto por fragmentos replegados o mal encajados como ya observara Íñiguez Almech hace más de medio siglo, aunque se quedara corto en el diagnóstico:

El palacio y casa de oficios, a escala menudísima, tienen algunas variantes con la definitiva, pero no fundamentales: son como primeras ideas. Un pliegue difícil de remediar ha trastornado algo la fotografía y parece mayor la diferencia. ${ }^{35}$

Más adelante se verá cómo tales «variantes» son más acusadas de lo que suponía el arquitecto, escasamente consideradas por autores posteriores a excepción de Verdú Ruiz ${ }^{36}$ y de Ortega Vidal y Sancho Gaspar ${ }^{37}$, que ofrecieron una

32. El documento sólo es conocido por la transcripción de Álvarez de Quindós: Descripción..., p. 221, sin prueba alguna sobre la fecha, por lo que caben dudas razonables para pensar en una datación anterior, entre 1577 y 1578, habida cuenta de que su contenido se refiere con todo detalle a las condiciones de la cimentación, sin apenas referencias a otras partes del edificio.

33. Todas las palabras o frases entrecomilladas proceden de ibid., pp. 216 a 220.

34. Sancho Gaspar: La Arquitectura..., p. 332, y Muñoz Garcinuño: «La Casa de Oficios...», p. 93, entre otros.

35. Íñiguez Almech: Casas Reales..., pp. 143-144.

36. Verdú Ruiz: «Casa de Oficios...», p. 52.

37. Ortega Vidal: «Hacia un catálogo razonable de la arquitectura de Juan de Herrera. Un criterio topográfico», en AA. VV.: Juan de Herrera, arquitecto real, Barcelona, 1997, p. 47 a 125 (pp. 71 a 74$)$. 
acertada hipótesis gráfica en 1997. Para manejar esta fuente cartográfica en sus justos términos ha sido necesario esperar a 2001, cuando la traza fue restaurada; ofrecemos el fragmento que abarca palacio y Casa de los Oficios (fig. 6) con la posición original de los edificios delineados.

Lo cierto es que la primera Casa de los Oficios ideada por Herrera se disponía en planta como un cuadrado casi perfecto de unos 460 pies de lado (127 m, aproximadamente), con su fachada principal al norte, porticada entre dos cuerpos ligeramente salientes, y una distribución interior resuelta en dos zonas separadas de norte a sur por el mencionado «tránsito descubierto»: la primera organizada en torno a los patinejos y destinada a los servicios de palacio; la segunda alrededor de un gran patio rectangular de proporción doble destinada al Cuarto de Caballeros (fig. 9). El esquema parece inspirado en el plano de la domus clásica con peristilo publicado por Fra Giocondo da Verona en su edición de Vitruvio ${ }^{38}$ (fig. 10) y también recuerda al núcleo principal de las fundaciones cartujas de la época, con su división entre zona de servicio y zona de clausura, la gran amplitud del patio mayor, la presencia de patios menores y la regularidad en la disposición de dependencias a su alrededor dentro de un estricto perímetro regular con arreglo simétrico, tal como se aprecia, por ejemplo, en la solución rectangular de Giovanni Vincenzo Casale -no obstante trece años posterior al proyecto de Aranjuez- para la Cartuja de Évora $^{39}$ (fig. 11), en la que ni siquiera falta el «tránsito descubierto», aunque con otra disposición.

En los documentos sobre adjudicación de destajos, de 1584, y en el pleito subsiguiente por discrepancias en la tasación de lo construido, de 1587, se encuentran más datos para determinar la evolución constructiva de la Casa de los Oficios y del cerramiento del Jardín del Rey, con significativas variaciones respecto de lo proyectado en la década anterior. Los contratos con los destajeros constan en la documentación del pleito, citados por Martín González ${ }^{40}$, y no dejan lugar a dudas sobre las seis partes adjudicadas, coincidentes con las que figuran, ya construidas, en representaciones como el dibujo de l'Hermite, de ca. 1588, y el cuadro del Museo del Prado, anterior a 1613: al maestro Pedro de Aranzábal y consortes se les encargaba el primer destajo en la parte que iba «desde la capilla Real hasta el pasado del Xardin que este lienço mira al mediodia con mas los tres arcos que miran al poniente y los otros tres arcos que miran al levante con

38. Vitruvio Polión, Marco: M. Vitruvius per Iocundum solito castigatior factus cum figuris et tabula ut iam legi et intelligi possit. Venecia, 1511, fols. 63r y 64v.

39. Vincenzo Casale, G., BNE, Dib/16/49/53, Planta de la Cartuja de Évora, 1590.

40. Martín González: «El Palacio de Aranjuez...», pp. 148-149. 
sus responsiones» ${ }^{41}$ (es decir, la galería exterior apoyada sobre el muro de cierre del Jardín del Rey y -ahora sí- el paso cubierto y descubierto hasta la Casa de los Oficios, constituido por tres tramos en arco de tipo adintelado que serían transformados en 1756 por Santiago Bonavía ${ }^{42}$ ); a Martín Jamba y compañeros les correspondió el segundo destajo «desde la letra $\mathrm{H}$ a la $\mathrm{Y}$ » (probablemente corresponda a la mitad de poniente del flanco septentrional, aunque siguiendo un orden lógico sobre plano debería indicarse «desde la letra $\mathrm{B}$ hasta la $\mathrm{C}{ }^{43}$ ); a Juan Ramírez y Juan de Buega se les adjudicaba como tercer destajo la mitad oriental del ala norte; a Juan, Lucas y Pedro de Villa les correspondió por cuarto destajo la mitad norte del ala de poniente y a Alonso de Aguilera y compañeros el quinto destajo en la mitad sur del mismo ala, partes que probablemente incluían la construcción de dependencias en torno a los patinejos; finalmente, el sexto destajo se refería a cierta «parte del patio real de la Casa de los Caballeros que mira al Mediodía» y quedaba comprendido en la parte señalada «desde la letra $\mathrm{H}$ hasta la $\mathrm{Y}$ », lo que remite sin duda a una traza con los seis destajos designados por letras desde la A hasta la Y (es decir, la correlativa I latina), según proponemos en nuestra restitución gráfica (fig. 12). El resto de la obra se dejaba para una fase posterior que se adjudicaría «a los que mejor ubieren cunplido su partida».

A juzgar por lo que se aprecia de lo ejecutado en planos de la Casa de los Oficios muy posteriores (como el encargado por José Merlo en 1785, fig. 13,

41. AGS, Casas y Sitios Reales, Leg. 254, fol. 55, Cédula Real y condiciones para la obra de la Casa de Servicios, Aranjuez, anterior al 4 de julio de 1584. En el mismo legajo se encuentra la escritura de contrato y condiciones con Aranzábal, con fecha 4 de julio de 1584, donde igualmente se hace referencia a «esta parte de la casa de oficios que por mandado de S. M. se hace en la dicha Aranxuez que es desde la capilla real hasta haber pasado del jardín que este lienço mira al mediodia, con mas los tres arcos que miran al poniente y los otros tres arcos que miran al levante con sus responsiones», así como los contratos restantes.

42. El estado actual de este pasaje, formado por dos arcos rebajados, data de la renovación de Bonavía, pero es posible hacerse una idea de su configuración original gracias a dos representaciones anteriores: en el cuadro anónimo del siglo XVII con la vista ideal del palacio (Patrimonio Nacional), probable ilustración del proyecto de Gómez de Mora, se muestra claramente una solución adintelada, pero con sólo dos vanos, si bien el tercero pudiera computarse en la esquina noroccidental de la propia Casa de Oficios, que es lo que se aprecia en el cuadro del Museo del Prado, probablemente anterior a 1613, como vimos, y en el dibujo de Pier Maria Baldi para el Viaje de Cosme III de Médicis por España, de 1669. Consta documentalmente el uso de formas adinteladas para los ángulos del edificio y para las puertas centrales de acceso, según quedó registrado por el arquitecto Pedro Caro Idrogo en sus informes de 1730.

43. En el trabajo de Martín González: «El Palacio de Aranjuez...», p. 248, consta «desde la letra $\mathrm{H}$ hasta la $\mathrm{Y}$, aunque debe de tratarse de una errata al repetirse la misma indicación para el sexto y último destajo (no hemos podido determinar si el error procede de la fuente, del investigador o de la imprenta). 
en el que se indican las partes antiguas $\left.{ }^{44}\right)$, la localización y la orientación de la planta no se ajustaron al proyecto de 1577 (sintetizado en el plano atribuido a Herrera), pues el edificio quedó desplazado más de cincuenta metros al este de la ubicación prevista, se alteró su proporción y se dispuso con un giro de noventa grados de la planta, de forma que las crujías en torno a los patinejos dejaron su posición norte para ocupar el sector de poniente (duplicados por simetría en el sector de oriente) y el patio mayor pasó de la posición extrema por el sur a ocupar el centro de la parte septentrional del conjunto, inicialmente destinada a albergar el Cuarto de Caballeros (Álvarez de Quindós se refiere a este patio como «quarto de Caballeros antiguo, que estaba principiado desde el reinado del Señor Don Felipe $I V{ }^{45}$ ). En definitiva, entre 1577 y 1584 se introdujo un nuevo proyecto por parte de Juan de Herrera.

La ampliación de este primer núcleo hacia el sur con el nuevo Cuarto de Caballeros en torno al llamado "Patio de Quadrado» ${ }^{46}$ habría sido prevista por Gómez de Mora (si no constaba ya en el segundo proyecto de Herrera), y de hecho fue comenzada por su costado de poniente, como se aprecia en el cuadro del Museo del Prado, aunque no sería retomada hasta el siglo XVIII, con la intervención de Pedro Caro Idrogo y Esteban Marchand (entre 1714 y 1732), proseguida por Santiago Bonavía (entre 1734 y 1759) y no completada hasta la etapa de Jaime Marquet al frente de la obra (entre 1759 y 1764), cerrando el nuevo patio hacia las caballerizas hasta conformar una planta que recuperaba la disposición inicial, aunque con unas dimensiones mucho mayores: 750 pies de largo y 450 de ancho (207 x $125 \mathrm{~m}$, aproximadamente), una superficie que lo superaba en más de un tercio y una proporción sensiblemente rectangular (fig. 14).

Esta digresión hacia la historia constructiva de la Casa de los Oficios viene justificada por lo que pueda esclarecer en relación con la propuesta del duque de Béjar, formulada en 1580, y su posible ejecución a partir de 1584, como se verá enseguida.

44. AGP, Proyecto de H. Merlo para las Casas de Oficios de Aranjuez, 1785, $\mathrm{n}^{\circ}$ 583-586 (el plano se realizaría por encargo del aposentador real José Merlo, aunque delineado por Juan de Milla y equipo, de acuerdo con Sanz de Miguel, Carlos, El Real Palacio de San Lorenzo de El Escorial en tiempos de Carlos IV, tesis doctoral dirigida por Aurora Rabanal Yus, Universidad Autónoma de Madrid, 2015, p. 75).

45. Álvarez de Quindós: Descripción..., pp. 221-222.

46. Ibid., p. 222. Álvarez de Quindós consideraba que el nombre del nuevo patio mayor no procedía de su forma, sino del apellido que tuvo el propietario de un corral boyero preexistente, el mayoral Juan Quadrado. 


\section{CONSECUENCIAS. INCORPORACIÓN PARCIAL DE LAS PROPUES- TAS AL PROGRAMA GENERAL DEL REAL SITIO}

Según los datos anteriores, entre la primera fase de obras de 1578-1580 y la reanudación de los trabajos cuatro años después, se verifican variantes que afectaron a la Casa de los Oficios en la orientación de su planta, en su desplazamiento hacia levante y en la conexión entre palacio y Oficios por medio de un pasaje, pero también cabe añadir la presencia de los pórticos perimetrales, otra de las novedades de la solución adoptada en 1584 en la que se desarrolla casi completamente la idea inicial de la arquería de fachada (sólo el frente sur carece de pórtico).

Como vimos, las propuestas del duque de Béjar para minimizar la presencia ofensiva de la Casa de los Oficios consistían precisamente en alejarlas del frente palaciego y en vincular el edificio de servicio al de residencia por medio de un pasaje o galería baja y alta, además de crear un espacio ajardinado de transición (fig. 15). Ciertamente la galería llegó a construirse cuatro años después, a partir de 1584, por lo que la idea del duque no habría sido echada «en la baraja». En cuanto a la deseada separación hacia el sur, se transformó en un desplazamiento del edificio hacia el este, de forma que el palacio y la Casa de los Oficios se mantenían paralelos a la misma corta distancia de 50 pies (unos 14 metros), pero ya no quedaban frente a frente: se lograba el objetivo propuesto por el duque con diferente solución. Pero si el camino de acceso conservaba su primera configuración (precisamente por ello se habilitaron los tres arcos mencionados en los documentos), también se impedía la posibilidad de desplegar el espacio verde del prado con sus espalderas, fuentes y bandas arboladas.

El apego del gobernador Samaniego al proyecto antiguo de Aranjuez quedó de manifiesto en sus prolijas anotaciones sobre los planos del palacio y en otro de 1728 , trazado por el arquitecto Caro Idrogo ${ }^{47}$, que incluye los jardines inmediatos al edificio (fig. 16), una obra que perdería su sentido tras la decisión de crear el nuevo y más extenso Jardín del Parterre, con diseño a la francesa a cargo de Esteban Marchand, a partir de 1730. En el plano de 1728 se reconocen los dos jardines privados del rey y de la reina y otro transversal unido a ellos, de superficie doble, que flanquea el costado oriental del palacio: ni más ni menos que los tres espacios representados en el plano de las Huertas de Picotajo (sin trazado de eras en ellos), y que también pueden apreciarse en las mencionadas representaciones del siglo XVII, ya con cuadros de setos bajos en los laterales

47. Servicio Geográfico del Ejército (SGE), no 113-2, Proyecto de reforma y ampliación del Palacio de Aranjuez por las crujías norte y este, $1^{\circ}$ de septiembre de 1728.

Ediciones Universidad de Salamanca / @®@@ Stud. his., H. ${ }^{a}$ mod., 40, n. 2 (2018), pp. 305-343 
y otro de mayor altura como delimitación oriental. En el plano dieciochesco se muestra, en cambio, un cerramiento de fábrica que permite prolongar el ándito meridional del Jardín del Rey con un segundo tramo hasta el río, dejando libre de cierre (salvo la protección de una baranda) todo el costado ribereño, tal como había sugerido el duque de Béjar siglo y medio antes, a falta de completar la obra con los cubos de comunicación. La propuesta del duque en 1580 no pretendía dar solución a este jardín transversal del palacio, sino definir un sencillo espacio exterior de transición, pero, considerando las semejanzas en el diseño adoptado y la prolongación del cerramiento hasta el río, cabe preguntarse si el plano de 1728 no refleja una cierta solución de compromiso entre lo que propuso Francisco de Zúñiga (asumido por el rey junto con su arquitecto) y lo que permitía la superficie disponible en el siglo XVIII ${ }^{48}$, una vez que el camino entre palacio y Casa de los Oficios se mantuvo en su primera situación.

Apartamiento de la Casa de los Oficios, galería de conexión y cierre murado hasta el río: ¿fueron propuestas vanas entre «otras muchas cosas inpertinentes» o se tomaron en consideración dentro del programa general de Aranjuez? Las evidencias que hemos expuesto apuntan desde luego hacia lo segundo; las anotaciones del secretario Vázquez y el aprecio del rey por las opiniones del duque, también. Lástima que el «rasguño», aunque no se perdiera entonces para ser usado, tampoco haya podido conservarse.

\section{FUENTES Y BIBLIOGRAFÍA}

\subsection{Fuentes}

\subsubsection{Fuentes documentales:}

Archivo General de Simancas (AGS), Sección Casa Real, Obras y Bosques (antigua Casas y Sitios Reales)

Archivo Histórico Nacional (AHN), Sección Nobleza, Fondo Osuna

Archivo General de Palacio (AGP)

Archivo del Instituto Valencia de Don Juan (AIVDJ)

Biblioteca Nacional de España (BNE)

Biblioteca de Palacio (BP)

48. Según Sanz Hernando: El jardín clásico madrileño..., pp. 309-310, el gobernador Samaniego deseaba completar el proyecto con una amplia plaza exterior en la única parte posible (al este), en cierto modo equivalente al área de transición propuesto por el duque en 1580 , aunque con distinto tratamiento. 
Instituto Geográfico Nacional (IGN)

Museo Nacional del Prado (MNP)

Servicio Geográfico del Ejército (SGE)

\subsubsection{Fuentes impresas:}

Anónimo: Le Ceremonial de la Cour d'Espagne, Livre I, qui contient l'etiquete de la Cour, transcrito de un original en castellano conservado en la Biblioteca de El Escorial y publicado en Barbeyrac, J.: Supplément au corps universel diplomatique du droit des gens, avec le cérémonial diplomatique des cours de l'Europe, mis en ordre et considérablement augmenté par Jean Barbeyrac. vol. 5, 1739.

Anónimo: «Relación inédita sobre el casamiento de la infanta Isabel, hija de los Reyes Católicos, con el Rey de Portugal, don Manuel, y otros datos sobre la muerte del Príncipe don Juan en Salamanca», en El Monasterio de Guadalupe, n 48, 15 de junio de 1918.

Cabrera de Córdoba, L.: Historia de Felipe II, Rey de España, Madrid, 1619, tomo II, p. 937 (seguimos la edición de José Martínez Millán y Carlos Javier de Carlos Morales, Valladolid, 1998).

Calvete de Estrella, J. C.: El felicíssimo viaje del muy alto y muy poderoso Príncipe don Phelippe (edición de Paloma Cuenca). Col. Fuentes, Sociedad Estatal para la Conmemoración de los Centenarios de Felipe II y Carlos V, Madrid, 2001.

Covarrubias y Orozco, S.: Tesoro de la Lengua Castellana o española. Imprenta de Luis Sánchez, Madrid, 1611.

Diccionario de Autoridades, Real Academia Española de la Lengua, Madrid, 1737.

Torres, J. de: Relacion del nacimiento y cristianísimo del serenisimo principe Don Fernando, bijo del católico Rey de España Don Philippe, y de la Reyna Doña Anna de Austria, nuestros señores. Compuesta a modo de romance por Iuan de Torres, vezino de Medina del Campo. Imprenta de Vicente Millis, Medina del Campo, 1572.

Vitruvio Polión, M.: M. Vitruvius per Iocundum solito castigatior factus cum figuris et tabula ut iam legi et intelligi possit. Giovanni Tridino, Venecia, 1511.

Zarco Cuevas, F. J.: Documentos para la historia del monasterio de San Lorenzo el Real de El Escorial. Tomo IV. Historia de varios sucesos y de las cosas notables que han acaecido en España y otras naciones desde el año de 1584 hasta el de 1603. Escrita por el P. Fray Jerónimo de Sepúlveda, el Tuerto, monje jerónimo de San Lorenzo el Real de el Escorial. Imprenta Helénica, Madrid, 1924.

\subsection{Bibliografía}

Aguilar Perdomo, M. del R.: «El palacio fuera de palacio: prácticas arquitectónicas y festivas en jardines históricos y literarios de la temprana Edad Moderna", en Anales de Historia del Arte, vol. 23, número especial (II), Universidad Complutense de Madrid, Madrid, 2013. 
Álvarez de Quindós y Baena, J. A.: Descripción histórica del Real Bosque y Casa de Aranjuez. Imprenta Real, Madrid, 1804.

Aníbarro Rodríguez, M. A.: La construcción del jardín clásico. Teoría, composición y tipos. Akal, Madrid, 2002.

Añón Feliú, C. y Sancho Gaspar, J. L. (eds.): Jardin y Naturaleza en el Reinado de Felipe II. Sociedad Estatal para la Conmemoración de los Centenarios de Felipe II y Carlos V, Aranjuez, 1998.

Barbeito Díez, J. M.: «Felipe II y la arquitectura. Los años de juventud», en Checa Cremades, Fernando: Felipe II: un príncipe del Renacimiento. Un monarca y su época. Sociedad Estatal para la Conmemoración de los Centenarios de Felipe II y Carlos V Madrid, 1998.

Barbeito Díez, J. M. y Ortega Vidal, J.: «Los artífices de las obras reales», en Añón Feliú, Carmen, y Sancho Gaspar, José Luis (eds.): Jardín y Naturaleza en el Reinado de Felipe II. Sociedad Estatal para la Conmemoración de los Centenarios de Felipe II y Carlos V, Aranjuez, 1998.

Bouza Álvarez, F.: «Ardides del arte. Cultura de corte. Acción política y artes visuales en tiempos de Felipe II», en Checa Cremades, Fernando (coord.): Felipe II: un príncipe del Renacimiento. Un monarca y su época. Sociedad Estatal para la Conmemoración de los Centenarios de Felipe II y Carlos V, Madrid, 1998.

Bouza Álvarez, F.: «Realeza, aristocracia y mecenazgo (del ejercicio del poder modo calamo)», en Egido Martínez, Aurora, y Laplana Gil, José Enrique (eds.): Mecenazgo y Humanidades en tiempos de Lastanosa. Homenaje a la memoria de Domingo Ynduráin. Col. Actas / Filología, Instituto de Estudios Altoaragoneses e Institución Fernando el Católico. Zaragoza, 2008.

Ceballos-Escalera Gila, A.: La insigne orden del Toisón de Oro. Palafox \& Pezuela, Madrid, 2001.

Checa Cremades, F.: Felipe II, mecenas de las artes. Nerea, Madrid, 1998.

Domínguez Garrido, U., y Muñoz Domínguez, J. (coords.): El Bosque de Béjar y las Villas de Recreo en el Renacimiento. Actas de las I, II, III y IV Jornadas de Estudio, Grupo Cultural San Gil, Béjar, 1994, 1997, 2000 y 2003.

Íniguez Almech, F.: Casas Reales y Jardines de Felipe II. Cuadernos de Trabajo de la Escuela Española de Historia y Arqueología, nº 1, CSIC, Delegación de Roma, Roma, 1952.

Luengo Añón, A.: Aranjuez, utopia y realidad. La construcción de un paisaje. Consejo Superior de Investigaciones Científicas, Instituto de Estudios Madrileños y Ediciones Doce Calles, Madrid, 2008.

Majada Neila, J. L.: «La 'G' de Guiomar», en Domínguez Garrido y Muñoz Domínguez (coords.): El Bosque de Béjar y las Villas de Recreo en el Renacimiento. Actas de las II Jornadas de Estudio, Grupo Cultural San Gil, Béjar, 1997.

Martín González, J. J.: «El Palacio de Aranjuez en el siglo XVI», en Archivo Español de Arte, t. XXXV, no 137, Instituto Diego Velázquez, CSIC, Madrid, 1962.

Martín Lázaro, A.: «Apunte cronológico del ducado de Béjar», en Béjar en Madrid, $\mathrm{n}^{\circ}$ 107, 1 de junio de 1921.

Ediciones Universidad de Salamanca / ف®@ Stud. his., H. ${ }^{a}$ mod., 40, n. 2 (2018), pp. 305-343 
Martín Lázaro, A.: «Los primeros duques», en Béjar en Madrid n 142, 16 de noviembre de 1922.

Martín Lázaro, A.: «Cronología de los duques de Béjar», en Béjar en Madrid n 145, 1 de enero de 1923.

Martínez Millán, J., y De Carlos Morales, C. J. (dir.): Felipe II (1527-1597). La configuración de la Monarquía hispana. Junta de Castilla y León, Valladolid, 1998.

Morán Turina, M., y Checa Cremades, F.: Las Casas del Rey. Casas de Campo, cazaderos y jardines, siglos XVI y XVII. El Viso, Madrid, 1986.

Muñoz Domínguez, J.: «Francisco II, arquitecto remedón. Una aproximación biográfica al duque Francisco de Zúñiga y Sotomayor como entendido en arquitectura y comitente», en Estudios Bejaranos, n 16, Centro de Estudios Bejaranos, Béjar, 2012.

Muñoz García, J.: «Nota cronológica sobre los Zúñigas, duques de Béjar y los Sotomayor, condes de Belalcázar», en Béjar en Madrid n 1792, 21 de julio de 1956.

Muñoz García, J.: «Cronología de los Estúñigas, señores de Béjar, y de los duques, sus sucesores», en AA. VV.: Ofrenda a la Santísima Virgen del Castañar, Excelsa Patrona de Béjar y su Comarca, t. II, Prensa Española, Madrid, 1963.

Muñoz Garcinuño, G.: «La Casa de Oficios de Aranjuez», en Cuadernos de Arte e Iconografía, t. 12, no 23, Seminario de Arte Marqués de Lozoya, Fundación Universitaria Española, Madrid, 2003.

Ortega Vidal, J.: «Hacia un catálogo razonable de la arquitectura de Juan de Herrera. Un criterio topográfico», en AA. VV., Juan de Herrera, arquitecto real. Lunwerg, Barcelona, 1997.

Pizarro Gómez, F. J.: Arte y espectáculo en los viajes de Felipe II (1542-1592). Col. Ensayos no 137, Ediciones Encuentro, Madrid, 1999.

Pizarro Gómez, F. J.: Relaciones de los reinados de Carlos V y Felipe II. Sociedad de Bibliófilos Españoles, vol. 2, Madrid, 1941.

Rodríguez López, G.: «Apuntes biográficos sobre los señores y duques de Béjar», en Rodríguez López, Gabriel, y Agero Teixidor, Vicente: Contribución al estudio de la Historia de Béjar. Colección de estudios y documentos. Edición del semanario La Victoria, Béjar, 1919.

Rojo Vega, A.: Documentación sobre los seis primeros duques de Béjar. Universidad de Valladolid, Valladolid, 2008.

Sancho Gaspar, J. L.: La Arquitectura de los Sitios Reales. Catálogo Histórico de los Palacios, Jardines y Patronatos Reales del patrimonio Nacional. Patrimonio Nacional y Fundación Tabacalera, Madrid, 1995.

Santonja, G.: El mecenazgo literario en la casa ducal de Béjar durante la época de Cervantes. Fundación Instituto Castellano y Leonés de la Lengua, col. Libros Singulares, no 10, Burgos, 2005.

Sanz Hernando, A.: El jardín clásico madrileño y los Reales Sitios. Ayuntamiento de Madrid, Madrid, 2009.

Ediciones Universidad de Salamanca / ف®@ Stud. his., H. ${ }^{a}$ mod., 40, n. 2 (2018), pp. 305-343 
Sanz de Miguel, C.: El Real Palacio de San Lorenzo de El Escorial en tiempos de Carlos $I V$, Tesis doctoral dirigida por Aurora Rabanal Yus, Universidad Autónoma de Madrid, 2015.

Vargas-Hidalgo, R.: Guerra y diplomacia en el Mediterráneo. Correspondencia inédita de Felipe II con Andrea Doria y Juan Andrea Doria. Col. Crónicas y Memorias, Ediciones Polifemo, Madrid, 2002.

Verdú Ruiz, M.: "Casa de Oficios y Casa de Infantes», en Riada: Estudios sobre Aranjuez, I. Plaza de San Antonio: Arte, Historia, Ciudad. Doce Calles, Aranjuez, 1989.

\section{ANEXOS}

\subsection{Anexo documental}

Archivo del Instituto Valencia de Don Juan (AIVDJ), Envío 7, Tomo II, Carta del duque de Béjar a Felipe II a través del secretario Mateo Vázquez de Leca, 3 de abril de 1580 (transcripción parcial).

[fol. 2r] Después de Pascua fui a Aranjuez y vi aquella maquina que muestra bien el dueño que tiene y holgueme mucho y los que somos remendones (sic) presumimos como si entendiesemos las cosas de la arquitetura y allí a los ministros de su Majestad di mi razon y paresioles serlo. Holgaria aber en algo acertado para que el gusto de su Majestad no fuese menos en este particular y aunque las cosas como las de allí el acertar o herrar (sic) es el seguir el gusto del dueño o serle contrario pues como le haya en una cosa no ai para que satisfacer a nadie con ella, y jusgue ser inconviniente el camino que pasa junto a la galeria del jardin y estar allí a la vista desta galeria la Casa de los Servicios y que aquel quarto por aquella parte no dexava de ofender a la vista al estar la casa delante y con hazerse alli entre la galeria y la casa un prado que corriese alrededor de toda esta galería y dando vuelta al rio guardando la proporsion y este prado con su espaldar y algunas fuentes que acompañasen y detras del espaldar arboledas que hiziesen la vista con mas compostura y gusto por que parese inconveniente el ruido y cosas que de fuersa estando tan cerca la casa a de ser juez dellas su Majestad y algunos ratos cansalle y asi ai tienpo ahora de que la Casa del Serviçio como abia de llegarse a la de su Majestad se haga la fabrica en el llano hazia la otra parte y no deshacer nada de lo hecho de la Casa del Servisio y desde la Casa del Servisio a la puerta que esta ordenada para la entrada del servisio una galeria baxa para que en tiempo de agua venga la vianda con mas acomodo y le tengan los que an de servir y por lo alto otra galeria descubierta para si acaso su Majestad alguna vez quisiese pasar a la Casa del Servicio fuese aquel el paso y no dexaria de adornar y el camino echalle 
por detrás de la casa de los serviçios [fol. 2v] y las quatro puertas de la capilla que salen al canpo demas de sus puertas de madera hazelles otras de rexa para en ocasiones que se ofresen de aver mucha jente este la capilla desenbarasada y puedan desde fuera oir misa y las que deven entrar pueden por de dentro de la casa y en la galeria que va haciendo pared al jardín que corre alrededor de la casa parese que yendo su Majestad por ella no tiene salida sin volver por donde ha ido y jusgue que con hazerse tres cubos pegados a la galería por la parte de afuera al prado que dixe arriba y estos cubos guardaren en ellos la fabrica como esta todo lo demas y sirvan de escaleras con puertas en lo baxo asi para el jardin como para el prado y el uno donde junta la galeria con la torre de la capilla y el otro a la esquina que la haze al un paño y al otro y el otro al remate de la galeria y para este remate no creo seria herrado hazer una torre no mas alta que la galería que fuese paradero della y la vista y sitio era galanisima y apazible sobre el rio y jardines y aquellos canpos y alamedas. He dicho mi razon; si lo fuere no esta perdido el rasguño y a no sello, echallo en la baraja como otras muchas cosas inpertinentes y v. m. perdone el dalle ocasion de perder este rato de tienpo que quien en tan tasado lo tiene no es justo ocupárselo, mas el oficio de los dolientes deste haze el sayo.

Al servicio de v. m. / El duque de Bejar (rubricado) 
JOSÉ MUÑOZ DOMÍNGUEZ

IDEAS DEL DUQUE DE BÉJAR PARA EL REAL SITIO DE ARANJUEZ EN 1580

Notas del secretario Mateo Vázques de Leca

Madrid AMV 1580

El Duque de Bejar, 3 de Abril

$[\ldots]$

Advierte de algunas cosas que le parecieron que convenían hazerse en la obra de Aranjuez y otras partes del donde estuvo después de Paschua.

En particular le parescio de inconveniente el camino que pasa junto a la galeria del jardín, y el estar a la vista della la Casa de los Oficios con que se ofendia.

Apunta que entre la galeria y la casa se hiziese un prado que corriese alrededor de la galeria dando vuelta al rio en proporcion y que a este prado cercase un espaldera con algunas fuentes en el, y que detrás de la espaldera se pusiese arboleda a proposito de la vista y compostura buelta la Casa de los Oficios que como haya de llegar a la de su Majestad se haga en el llano hazia la otra parte sin deshacer nada de lo hecho, y que se haga una galeria baxa dende la Casa de los Oficios a la puerta por donde ha de entrar el servicio para que se lleve en tiempo de agua con comodidad la vianda.

Que por lo alto desta galeria baxa se haga otra descubierta para quando su Majestad quisiese pasar a la Casa de los Oficios.

Que el camino se heche por detrás de la Casa de los Oficios.

Que las quatro puertas de la Capilla que salen al campo demas de las de madera se pusiesen rexas para que quando hubiese mucha gente pudiesen oyr de fuera desembaraçando la Capilla.

Que para que su Majestad tenga salida de la galeria que haze pared al jardín, que corre alrededor de la casa sin volver por donde ha ydo, se hiziesen tres cubos pegados a la galeria por la parte de fuera para que sirvan de escaleras, para salir al jardín y al prado, el un cubo donde junta la galeria con la torre de la capilla el otro al esquina que haze el un paño y el otro, el tercero al remate de la galeria pareciéndole que aquí se podria hazer una torre no mas alta que la galería.

Ediciones Universidad de Salamanca / 요 Stud. his., H. ${ }^{a}$ mod., 40, n. 2 (2018), pp. 305-343 


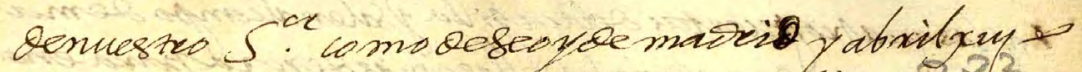

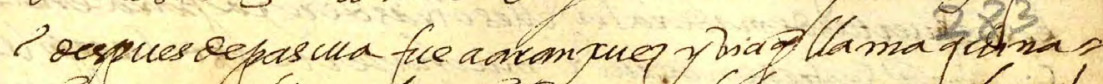

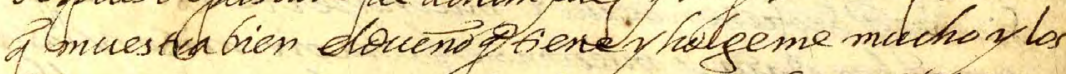
promes vemen oones pefum inos camo fientenstere- mos las cosas detardquiterua alli alos mi nisticos oesu

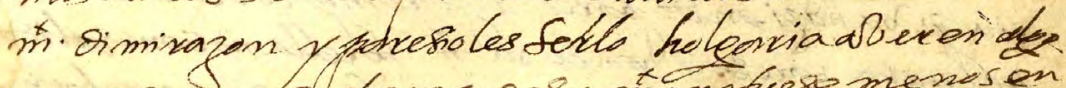

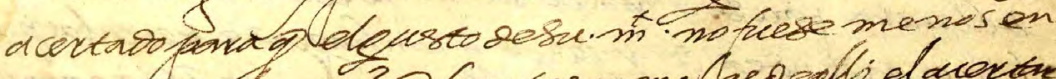

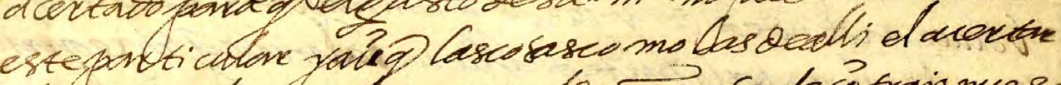

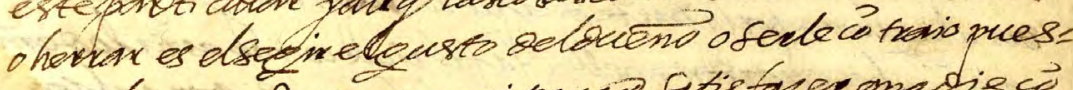

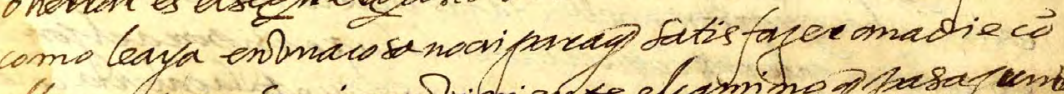

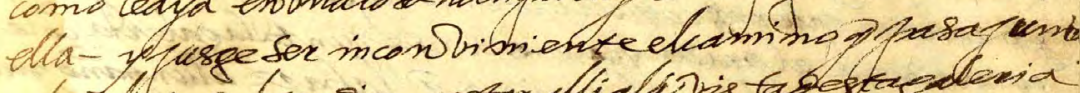
wacenteria od forsin yeston allialevis tabertazed

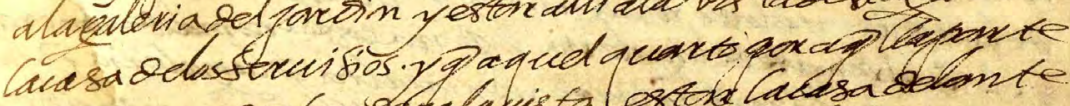

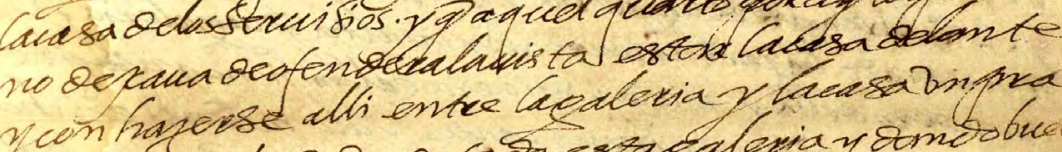

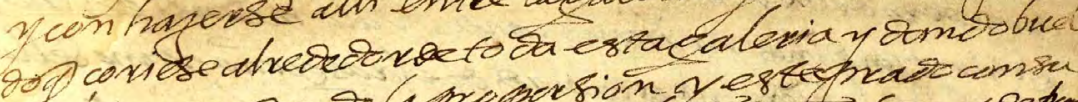

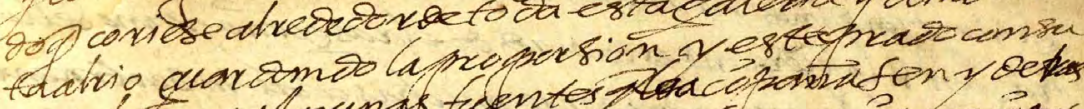

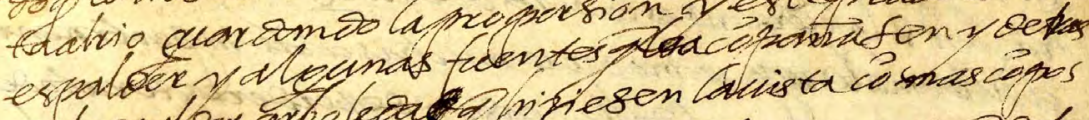

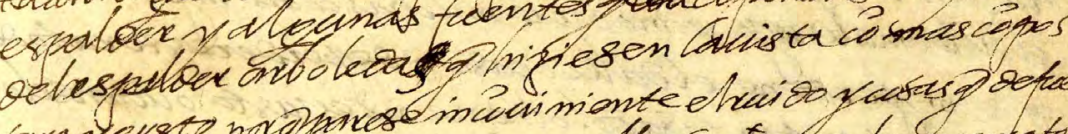

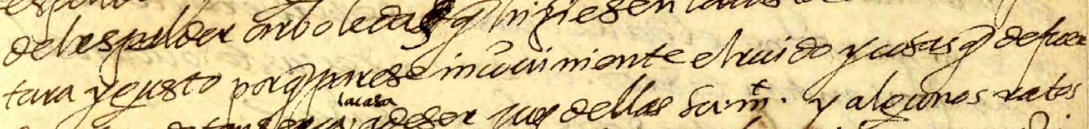

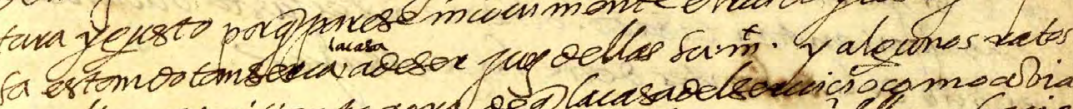

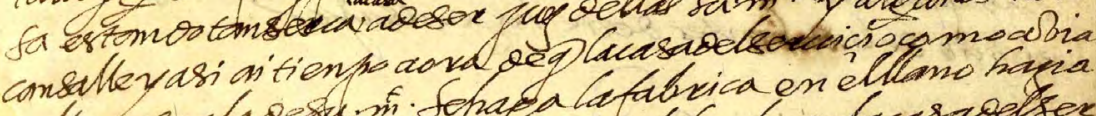

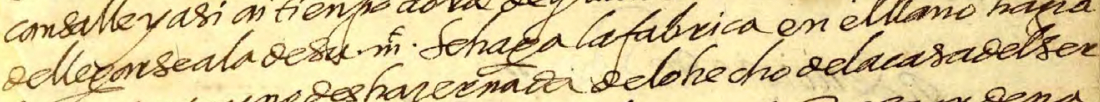

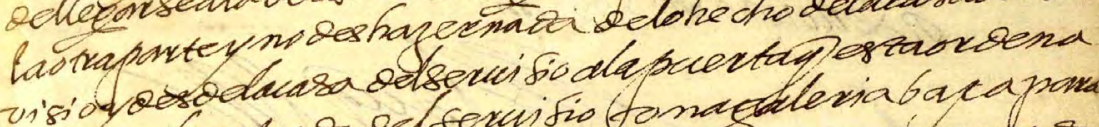

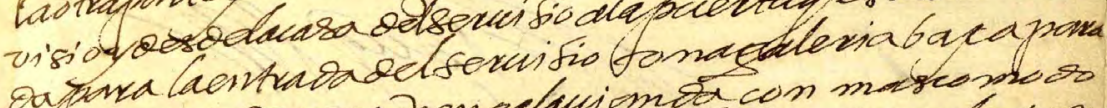

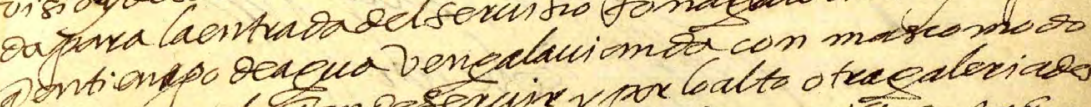

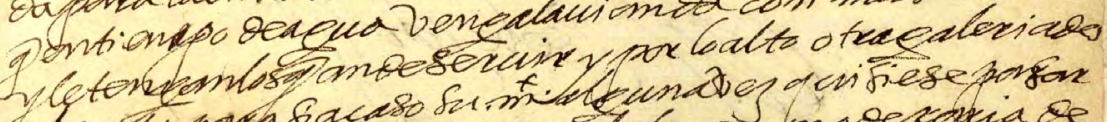

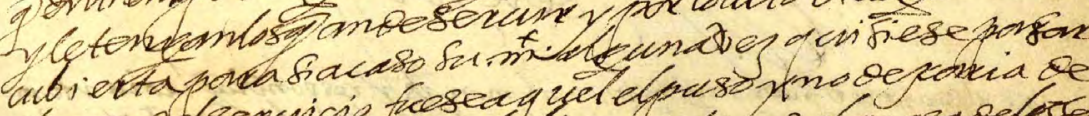

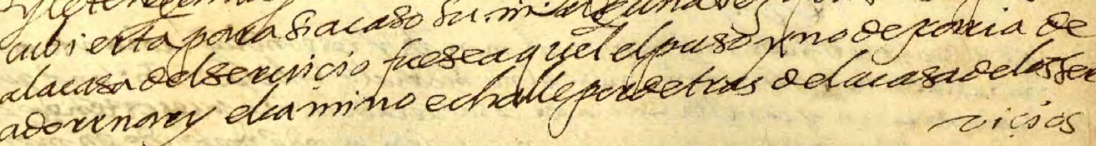

Figura 1. Carta del duque de Béjar a Mateo Vázquez de Leca (Archivo del Instituto Valencia de Don Juan, Envío 7. T. II, 110, 3 de abril de 1580, fol. 2r).

Ediciones Universidad de Salamanca / 


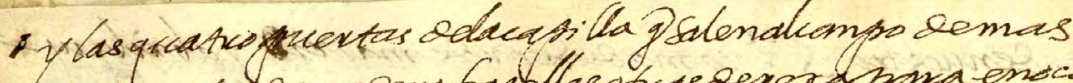

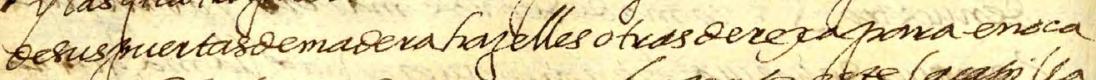
fionesg feofresen ocucer muchapente tefte lacepsila

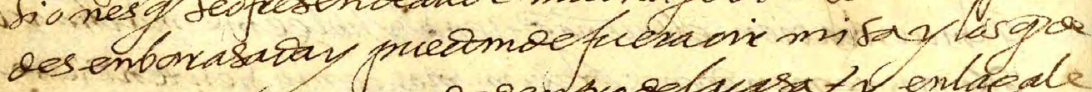

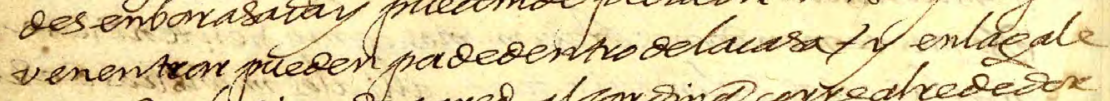

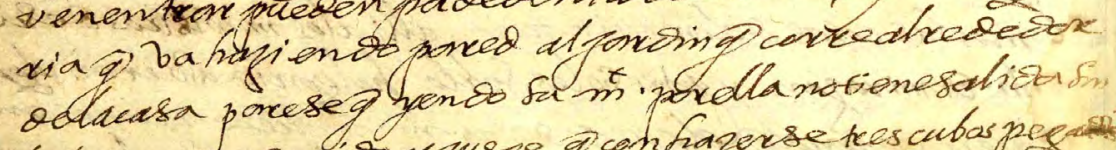

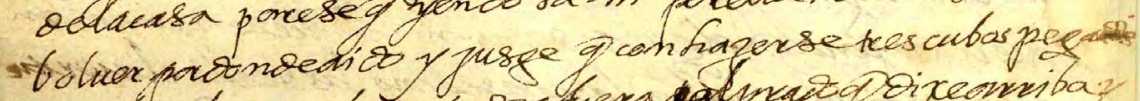

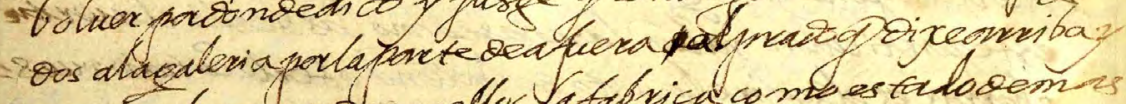

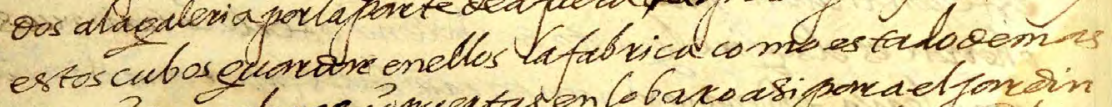

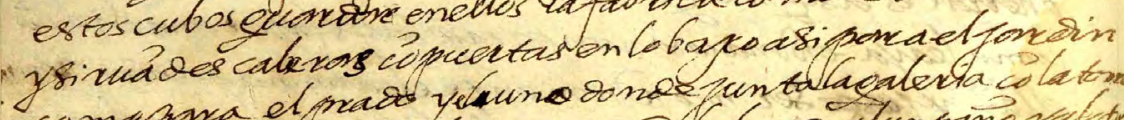

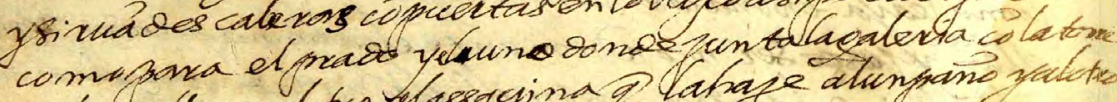

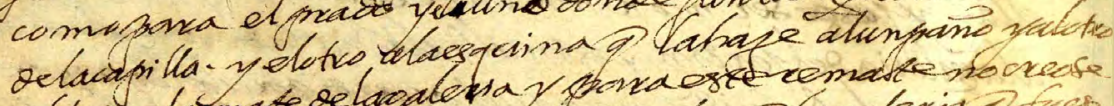

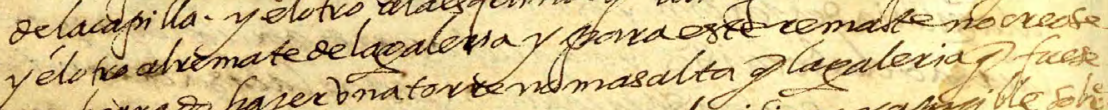
via hemaso hajexbrator re

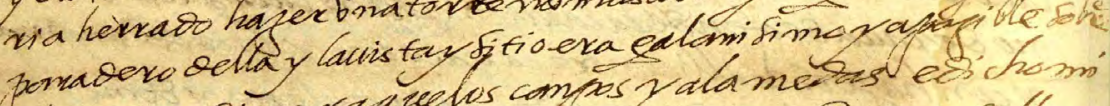

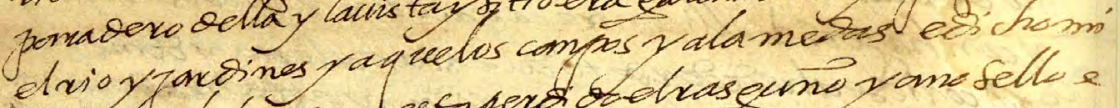

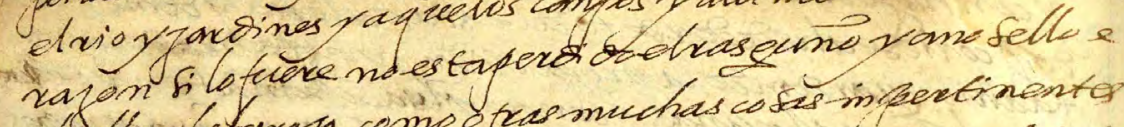

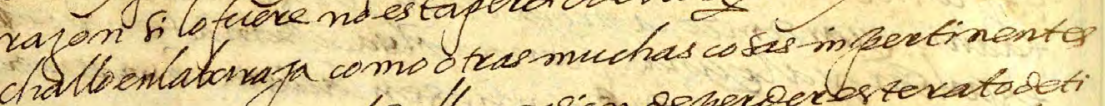
y. in pexoone eloalle ocasion deperoex bstevatodeti emporitrientam tasado lotione no esfus to ouponselo mas

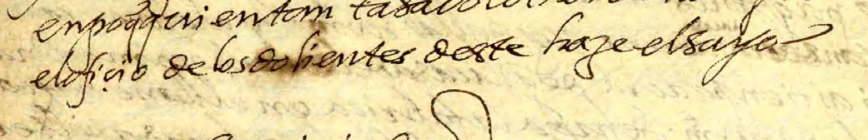

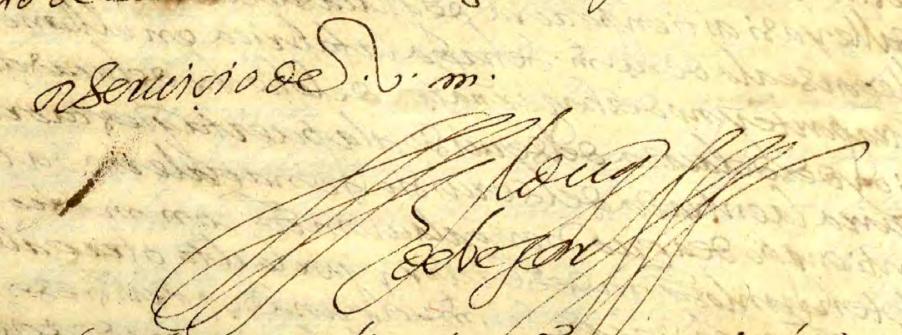

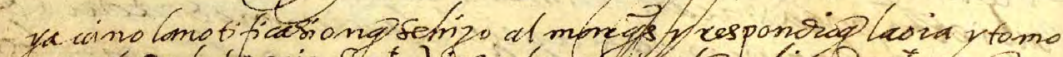

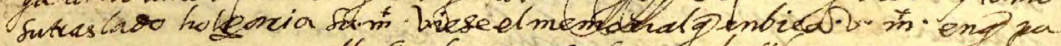

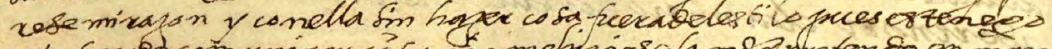

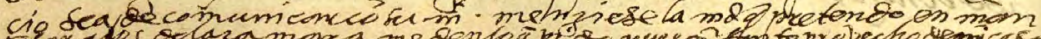

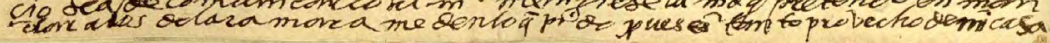

Figura 2. Carta del duque de Béjar a Mateo Vázquez de Leca (Archivo del Instituto Valencia de Don Juan, Envío 7. T. II, 110, 3 de abril de 1580, fol. 2v).

Ediciones Universidad de Salamanca / 요 Stud. his., H. ${ }^{a}$ mod., 40, n. 2 (2018), pp. 305-343 


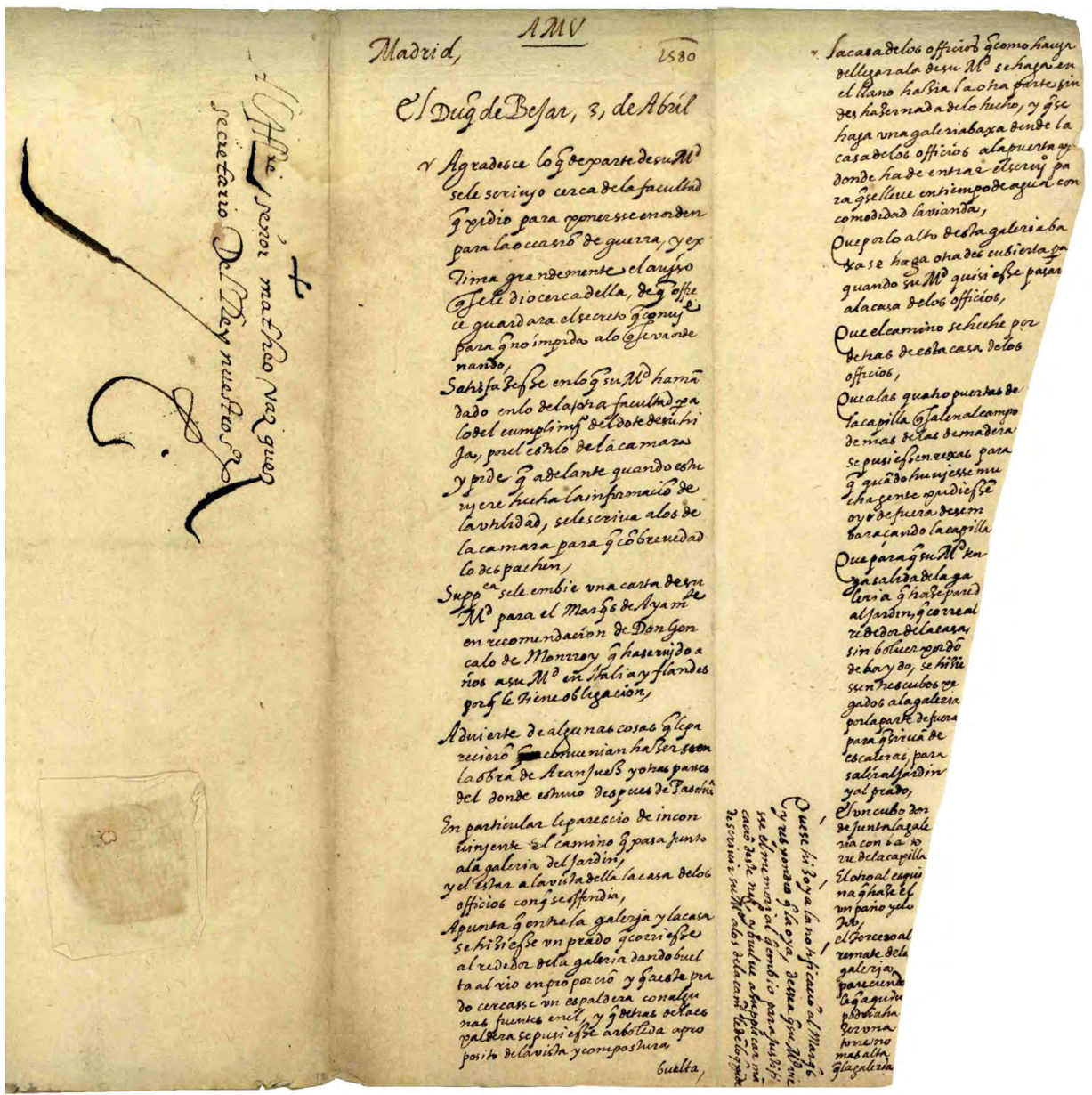

Figura 3. Notas del secretario Mateo Vázquez (Archivo del Instituto Valencia de Don Juan, Envío 7. T. II, 110, folio adicional, 3 de abril de 1580).

Ediciones Universidad de Salamanca / @®@@ Stud. his., H. ${ }^{a}$ mod., 40, n. 2 (2018), pp. 305-343 
JOSÉ MUÑOZ DOMÍNGUEZ

IDEAS DEL DUQUE DE BÉJAR PARA EL REAL SITIO DE ARANJUEZ EN 1580

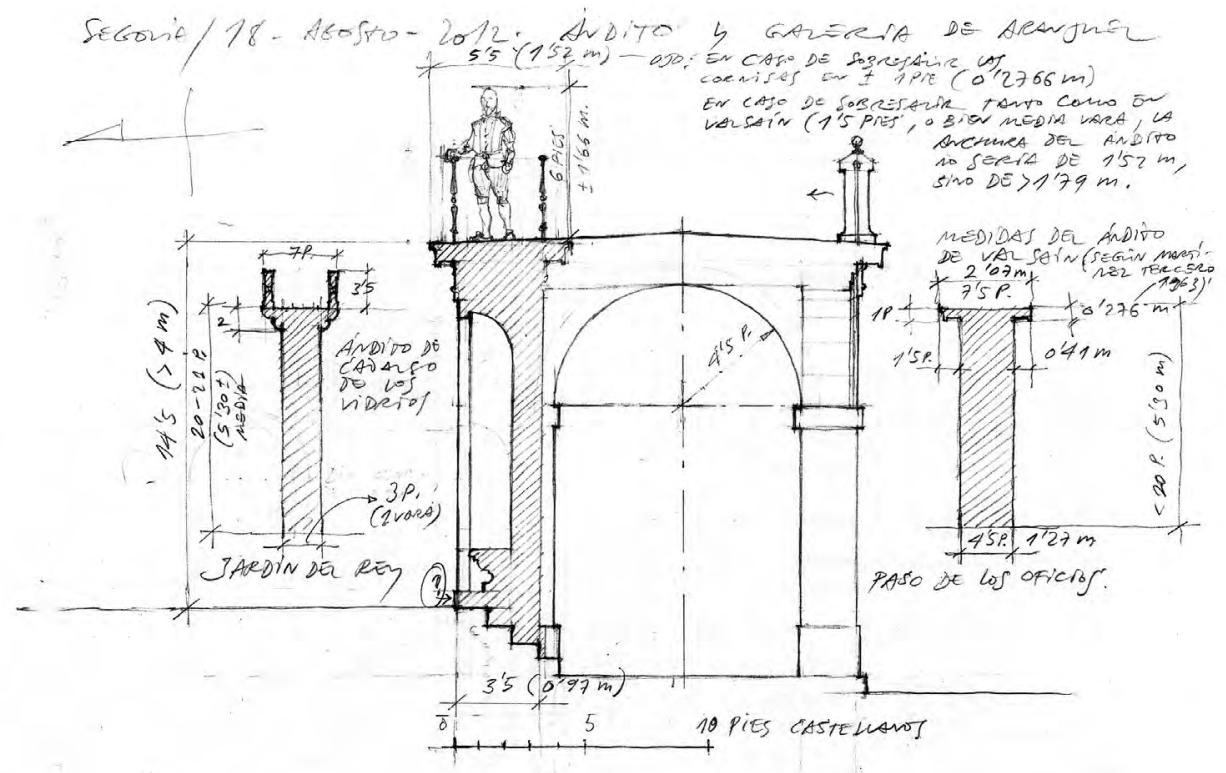

Figura 4. Secciones de los ánditos de Cadalso de los Vidrios, Valsaín y Aranjuez (croquis comparativo de José Muñoz Domínguez, 2012).

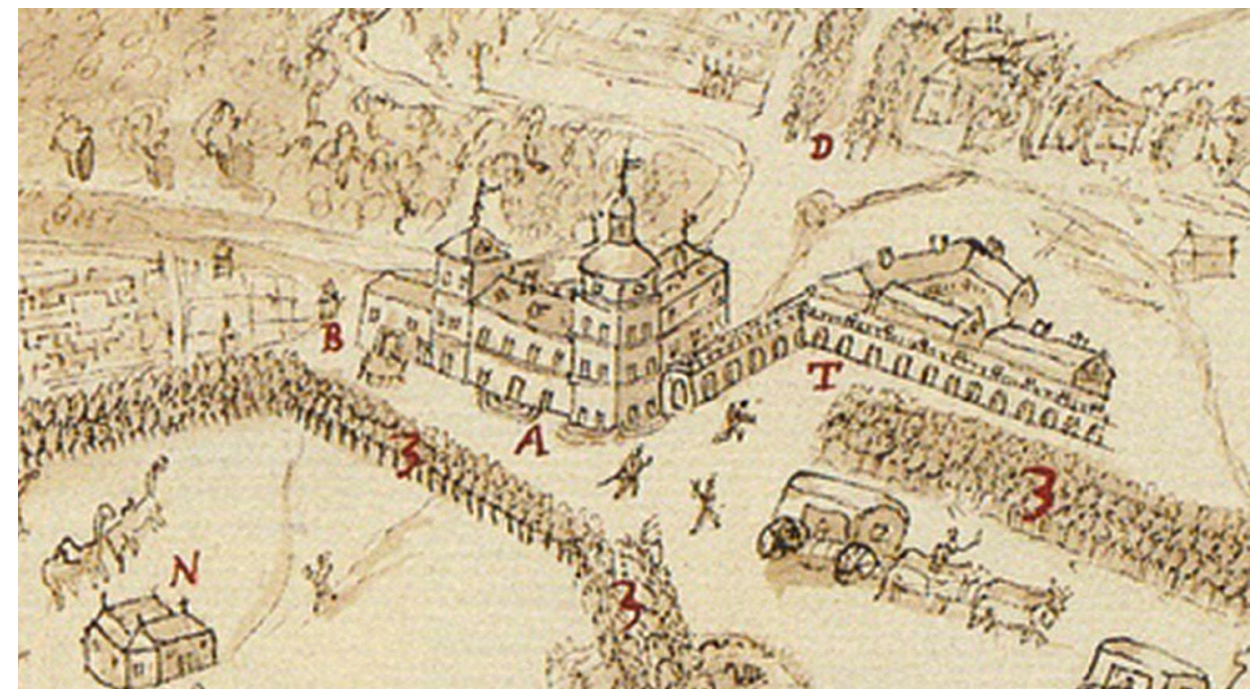

Figura 5. Dibujo del conjunto de Aranjuez por Jehan l'Hermite, ca. 1588, Biblioteca Real Alberto I, Bruselas (fragmento).

Ediciones Universidad de Salamanca /

Stud. his., H. ${ }^{a}$ mod., 40, n. 2 (2018), pp. 305-343 


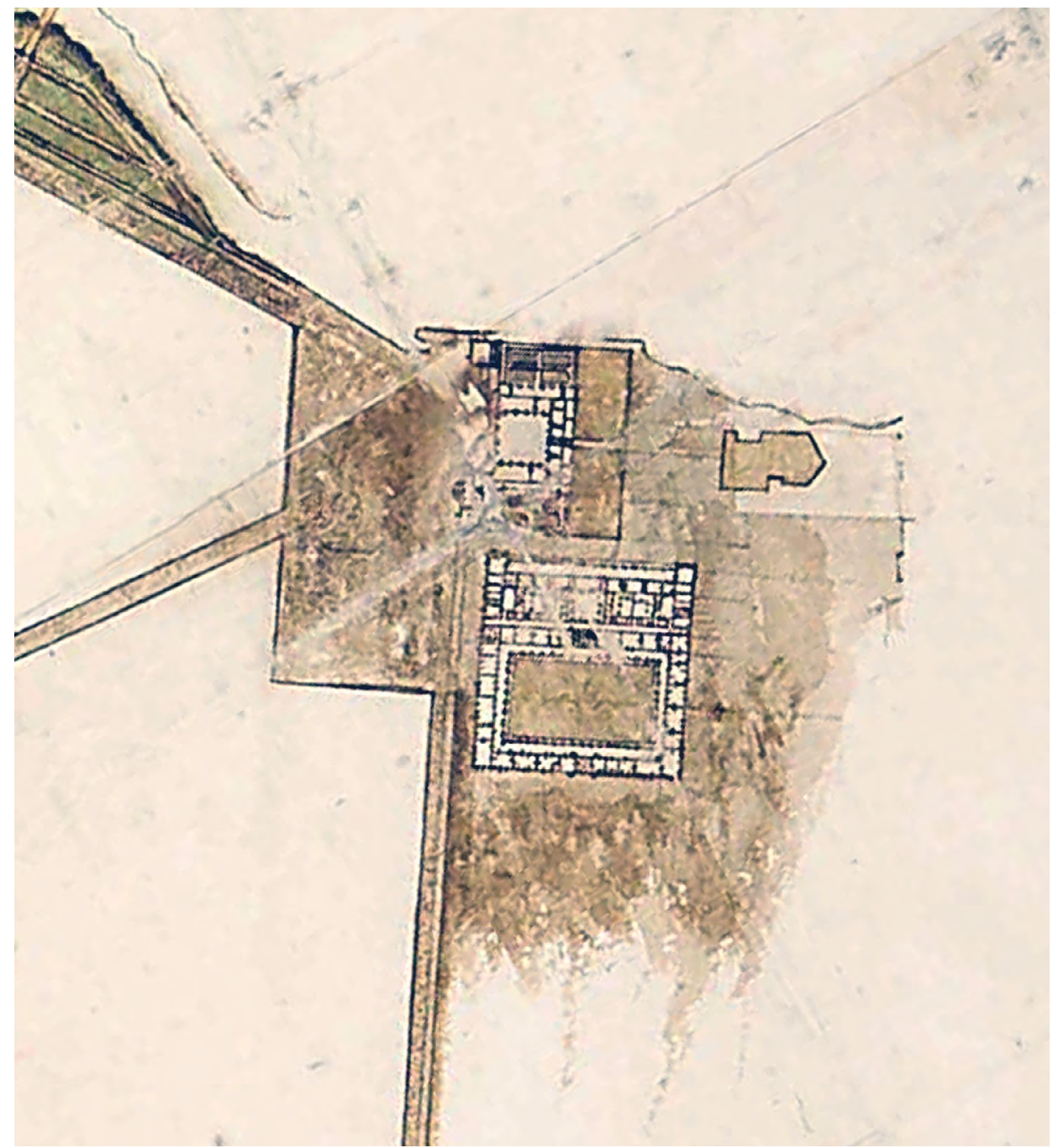

Figura 6. Fragmento del Plano de las Huertas de Picotajo, con el Palacio Real y la Casa de Oficios, atribuido a Juan de Herrera, ca. 1577-1578 (Biblioteca del Palacio Real, dib. IX-M-242, fasc. 2, 3-4, (C) Patrimonio Nacional). 


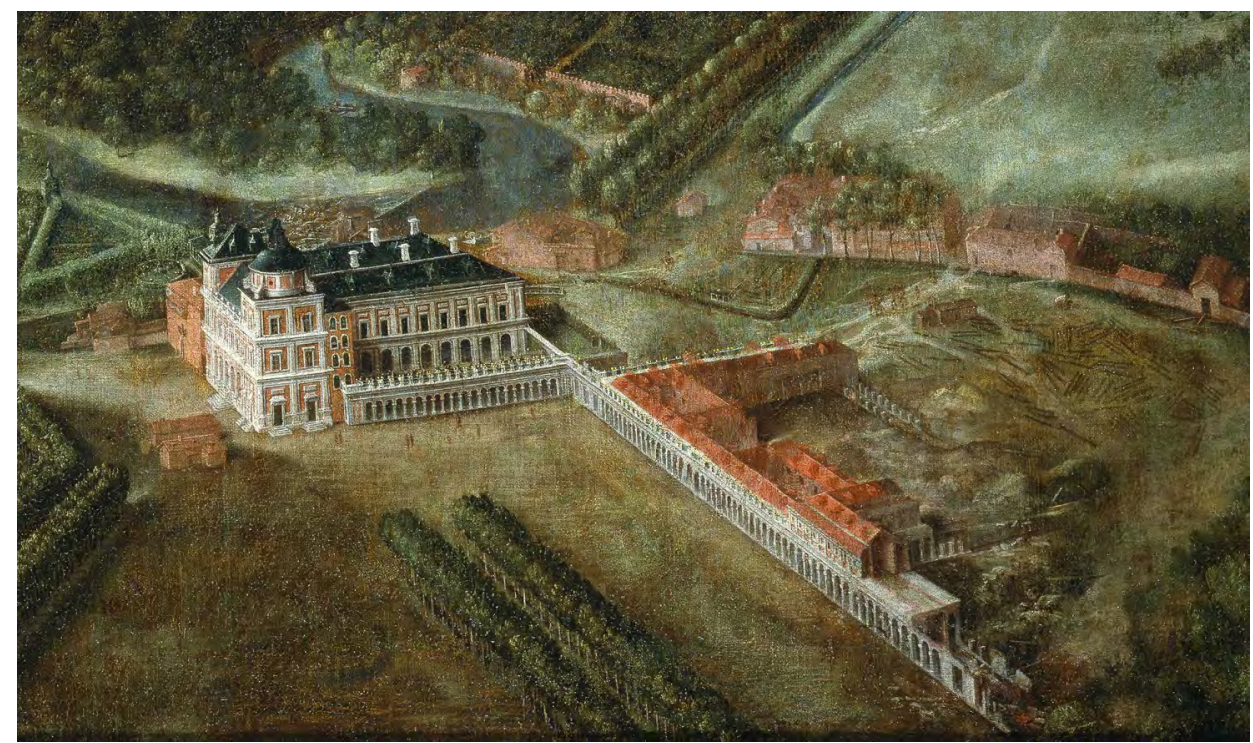

Figura 7. Vista del Real Sitio de Aranjuez, ca. 1613, fragmento (Museo Nacional del Prado, nº P07090).

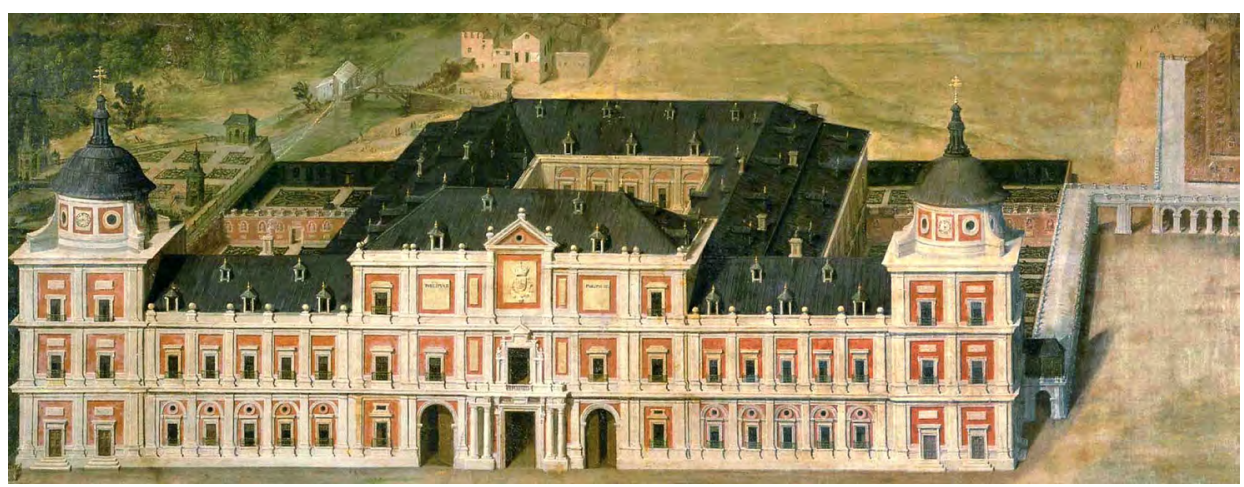

Figura 8. Vista ideal del Palacio de Aranjuez, ca. 1636, fragmento (Palacio de El Escorial, () Patrimonio Nacional).

Ediciones Universidad de Salamanca / ف®@ Stud. his., H. ${ }^{a}$ mod., 40, n. 2 (2018), pp. 305-343 


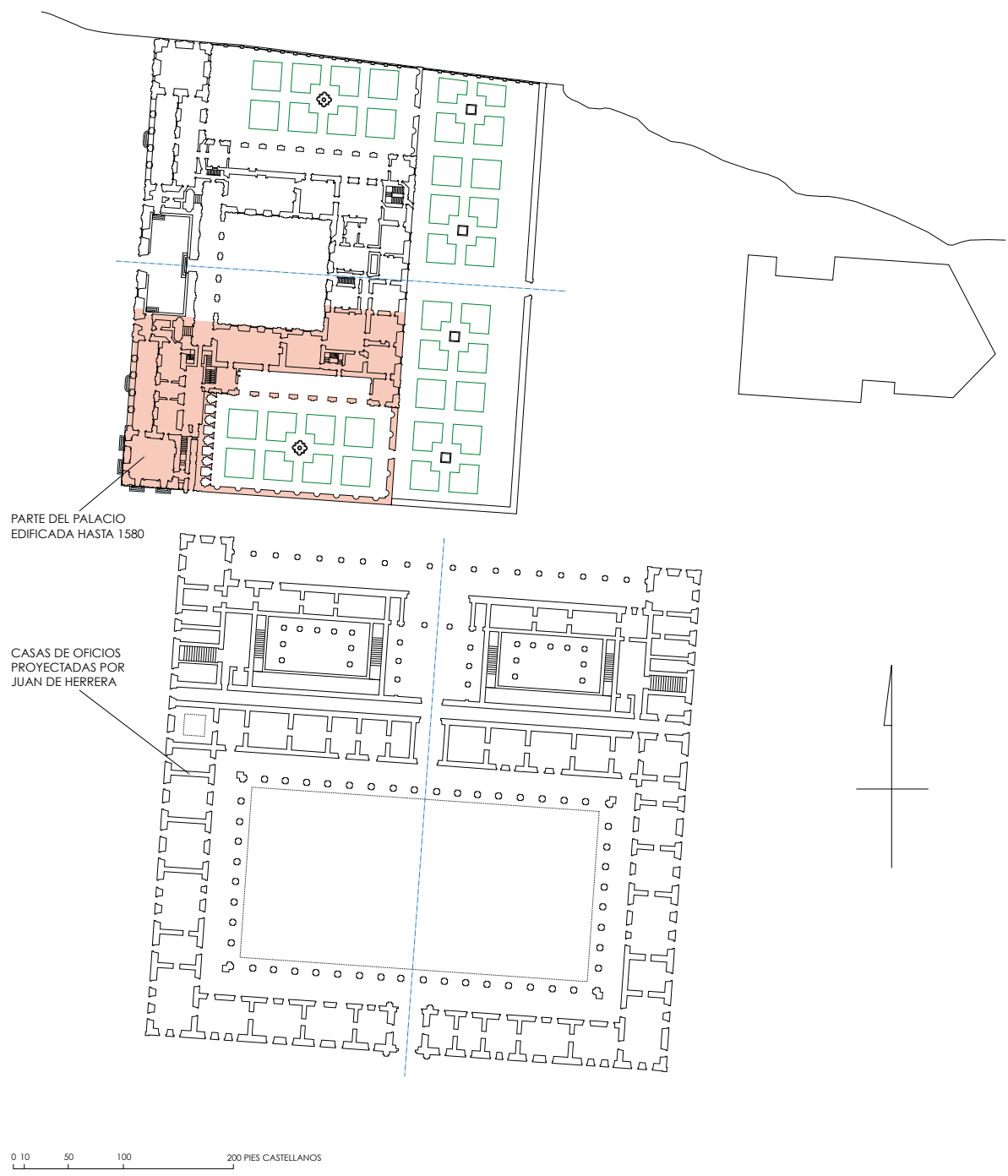

REAL SITIO DE ARANUEZ. PALACIO Y CASA DE LOS OFICIOS

Estado de proyecto a partir del plano de conjunto atribuido a Juan de Herrera Biblioteca de Palacio, IX-M-242, fasc. 2 (4), ca. 1577-1578

Figura 9. Hipótesis gráfica del primer proyecto de Juan de Herrera para la Casa de los Oficios, 1577 (plano de José Muñoz Domínguez, 2017).

Ediciones Universidad de Salamanca / 요 Stud. his., H. ${ }^{a}$ mod., 40, n. 2 (2018), pp. 305-343 


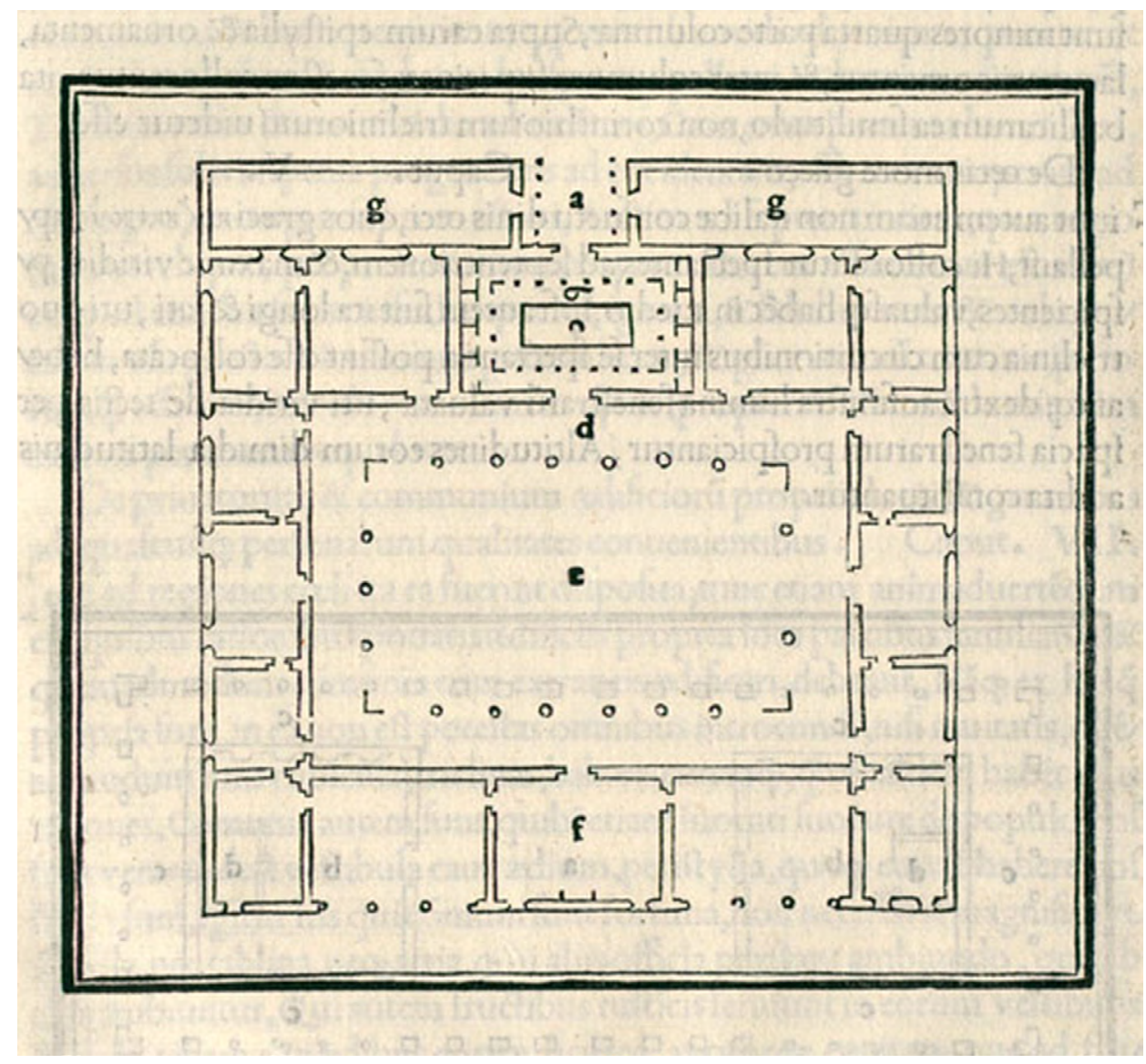

Figura 10. Plano de la domus clásica en la edición de Vitruvio por Fra Gionondo da Verona, 1511, fol. 63 r.

Ediciones Universidad de Salamanca / 


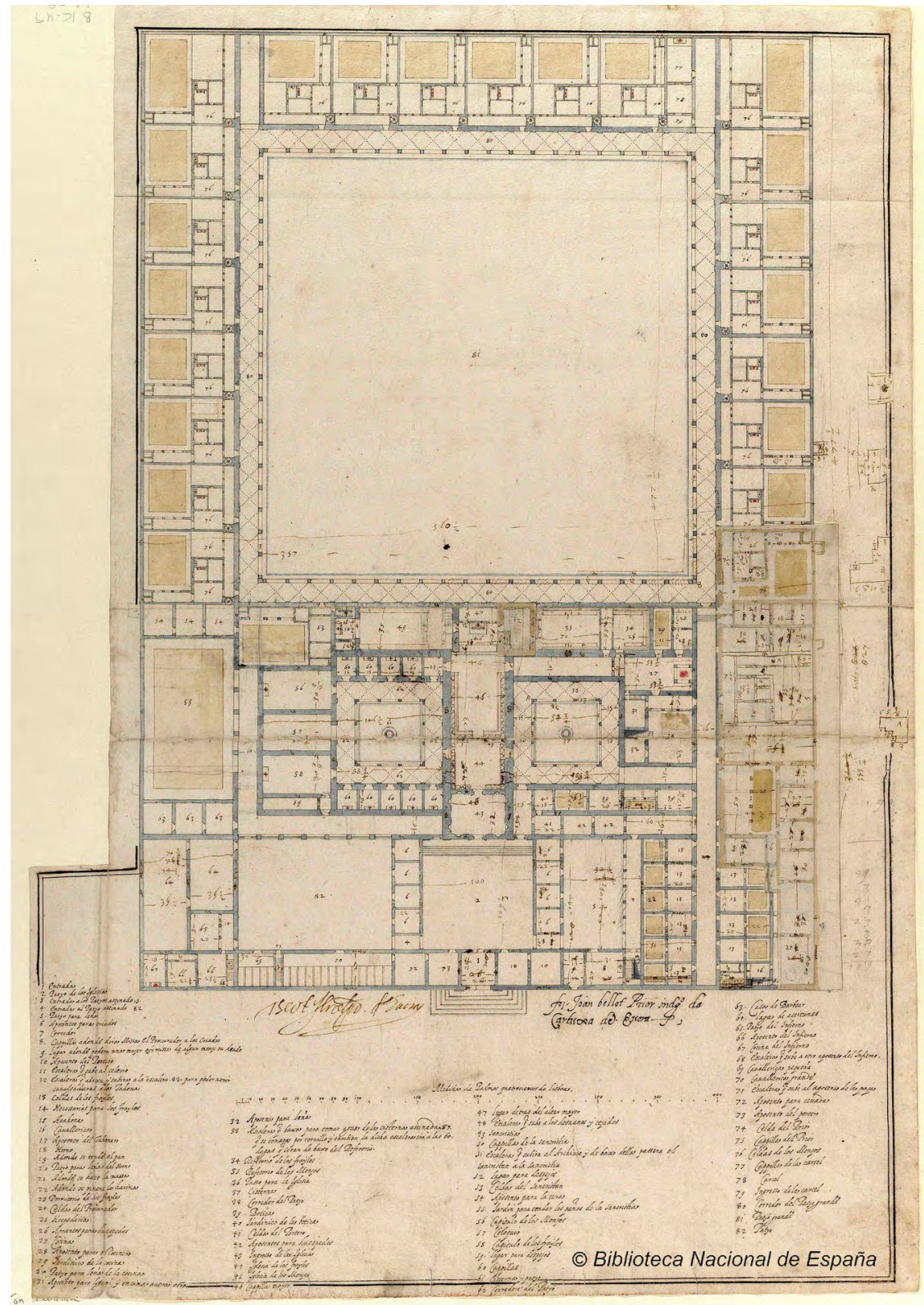

Figura 11. Proyecto de Giovanni Vincenzo Casale para la Cartuja de Évora, 1590 (Biblioteca Nacional de España, DIB/16/49/53).

Ediciones Universidad de Salamanca / 요 Stud. his., H. ${ }^{a}$ mod., 40, n. 2 (2018), pp. 305-343 


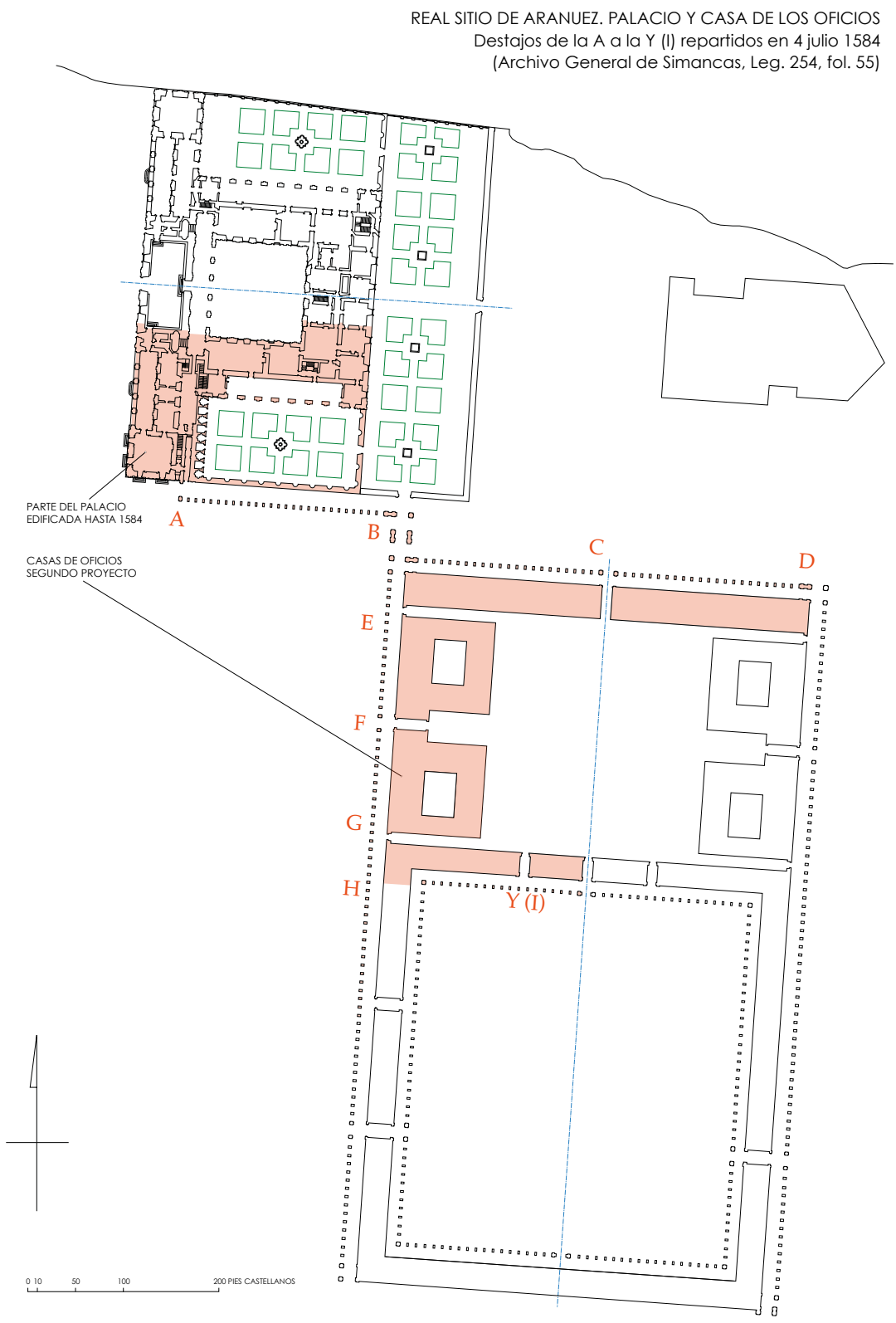

Figura 12. Hipótesis gráfica del segundo proyecto de Juan de Herrera para la Casa de los Oficios, 1584, y localización de los seis primeros destajos (plano de José Muñoz Domínguez, 2017).

Ediciones Universidad de Salamanca / @®@@ Stud. his., H. ${ }^{a}$ mod., 40, n. 2 (2018), pp. 305-343 
JOSÉ MUÑOZ DOMÍNGUEZ

IDEAS DEL DUQUE DE BÉJAR PARA EL REAL SITIO DE ARANJUEZ EN 1580

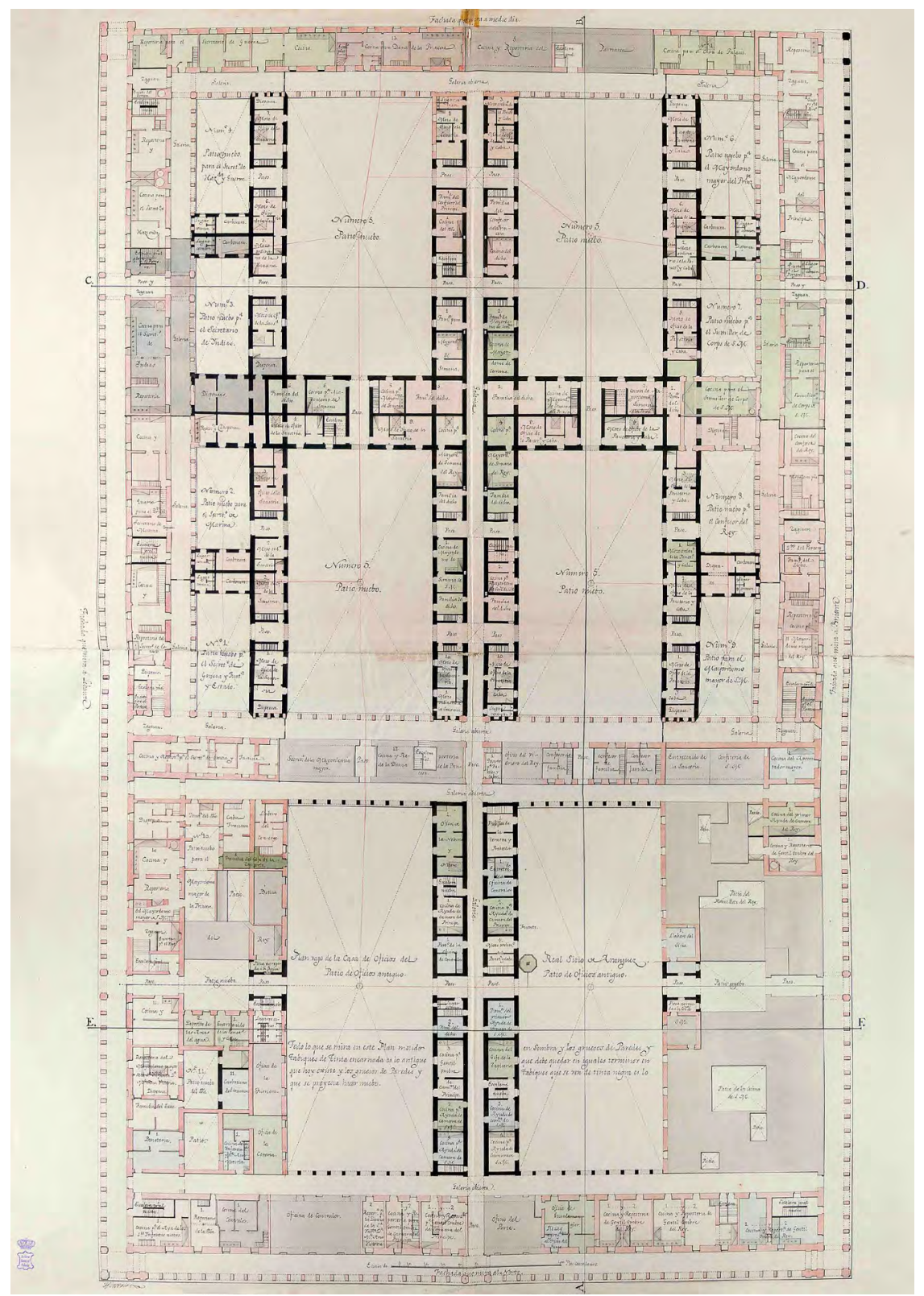

Figura 13. Proyecto de H. Merlo para la Casa de los Oficios de Aranjuez, $\mathrm{n}^{\circ}$ 583-586, planta baja, 1785 (Archivo General de Palacio, $n^{\circ}$ 583-586, () Patrimonio Nacional).

Ediciones Universidad de Salamanca / అ@@ Stud. his., H. ${ }^{a}$ mod., 40, n. 2 (2018), pp. 305-343 
JOSÉ MUÑOZ DOMÍNGUEZ

IDEAS DEL DUQUE DE BÉJAR PARA EL REAL SITIO DE ARANJUEZ EN 1580

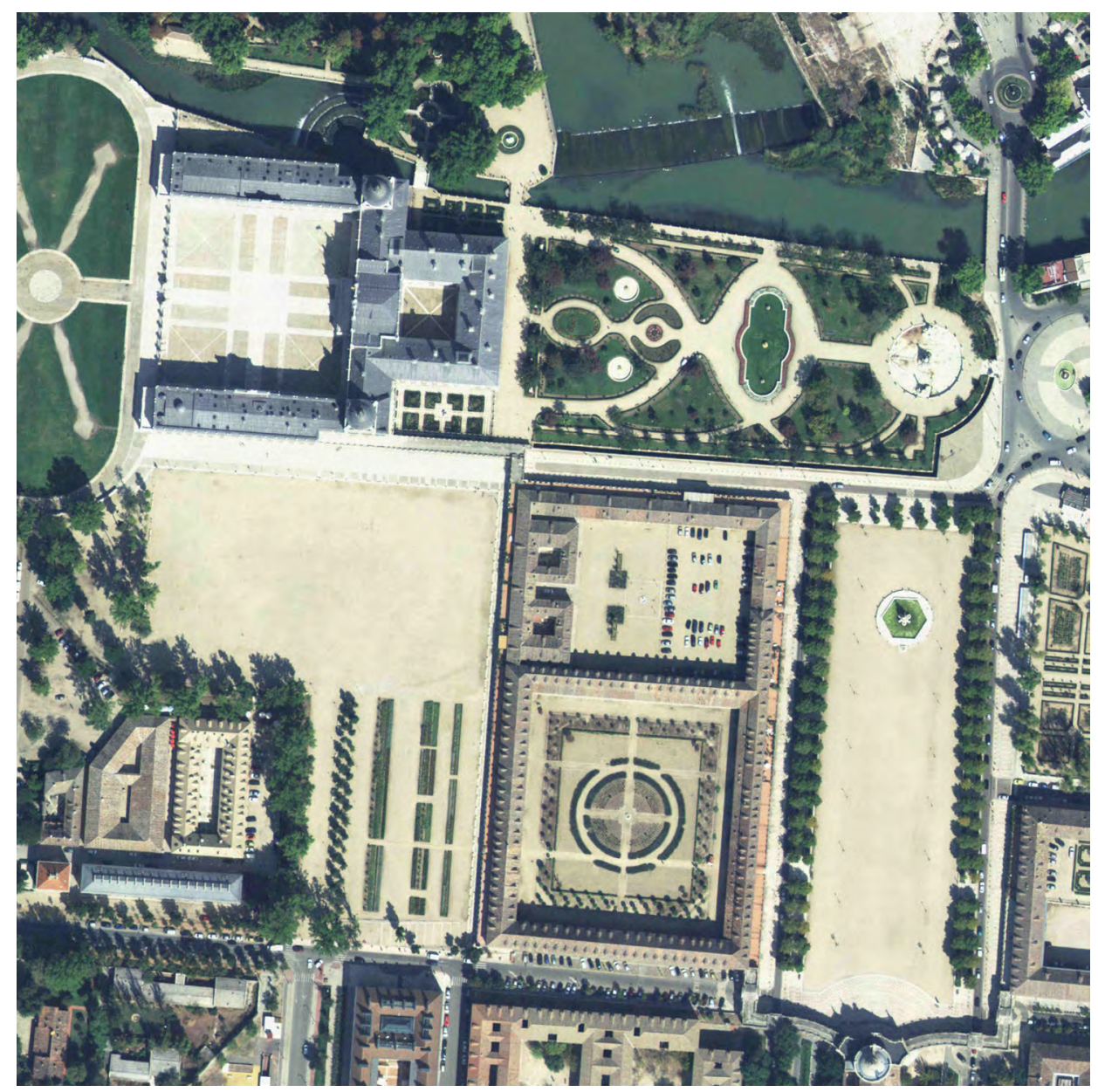

Figura 14. Imagen de satélite del palacio y la Casa de los Oficios de Aranjuez (Instituto Geográfico Nacional, 2012).

Ediciones Universidad de Salamanca / అ@@ Stud. his., H. ${ }^{a}$ mod., 40, n. 2 (2018), pp. 305-343 


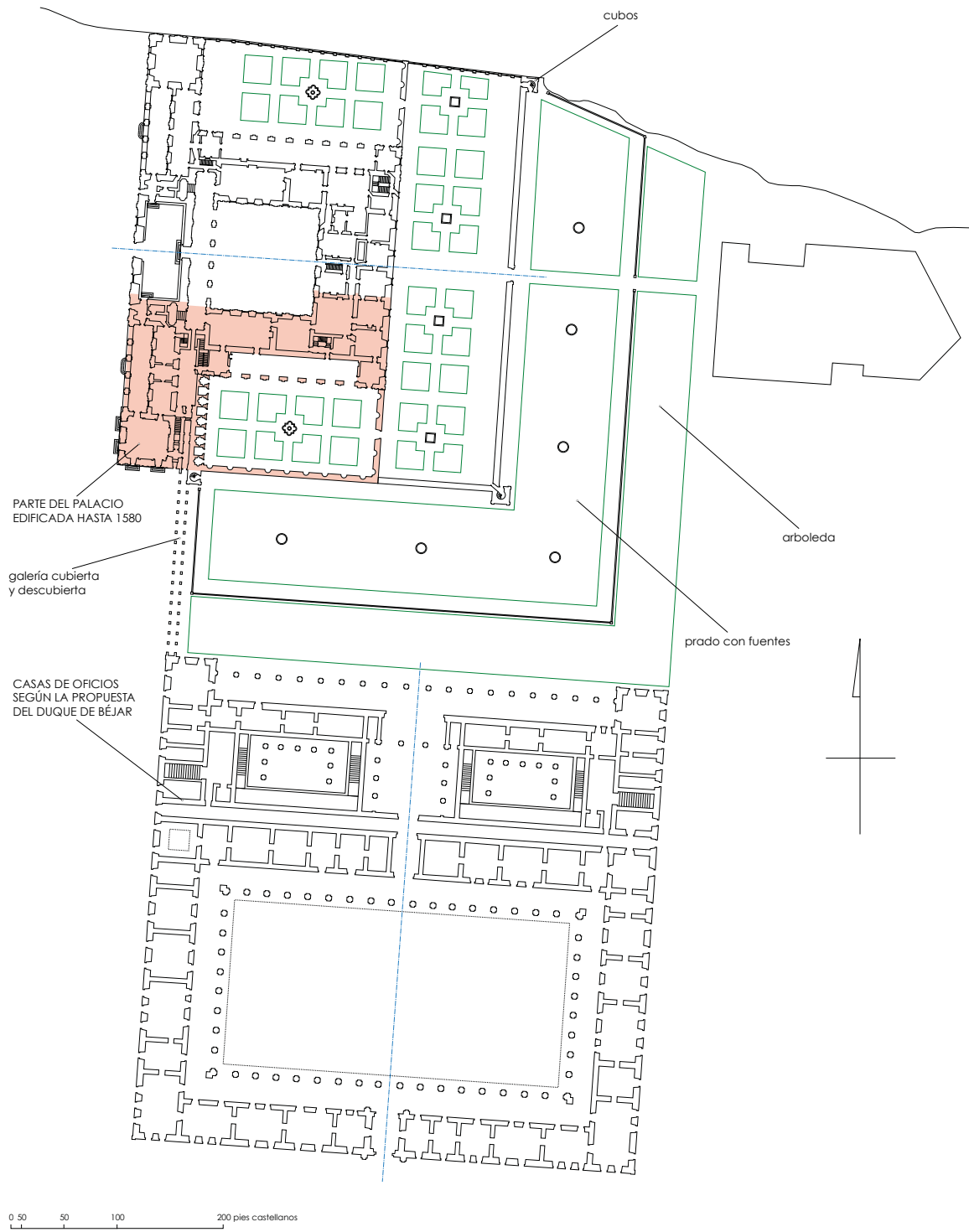

REAL SITIO DE ARANUEZ. PALACIO Y CASA DE LOS OFICIOS

Hipótesis con las propuestas del duque de Béjar en 1580

(a partir de Archivo del Instituto Valencia de Don Juan, Envío 7, T. II, 110, 3 de abril de 1580)

Figura 15. Hipótesis gráfica de las propuestas del duque de Béjar para Aranjuez, 1580 (plano de José Muñoz Domínguez, 2017).

Ediciones Universidad de Salamanca / @®@@ Stud. his., H. ${ }^{a}$ mod., 40, n. 2 (2018), pp. 305-343 


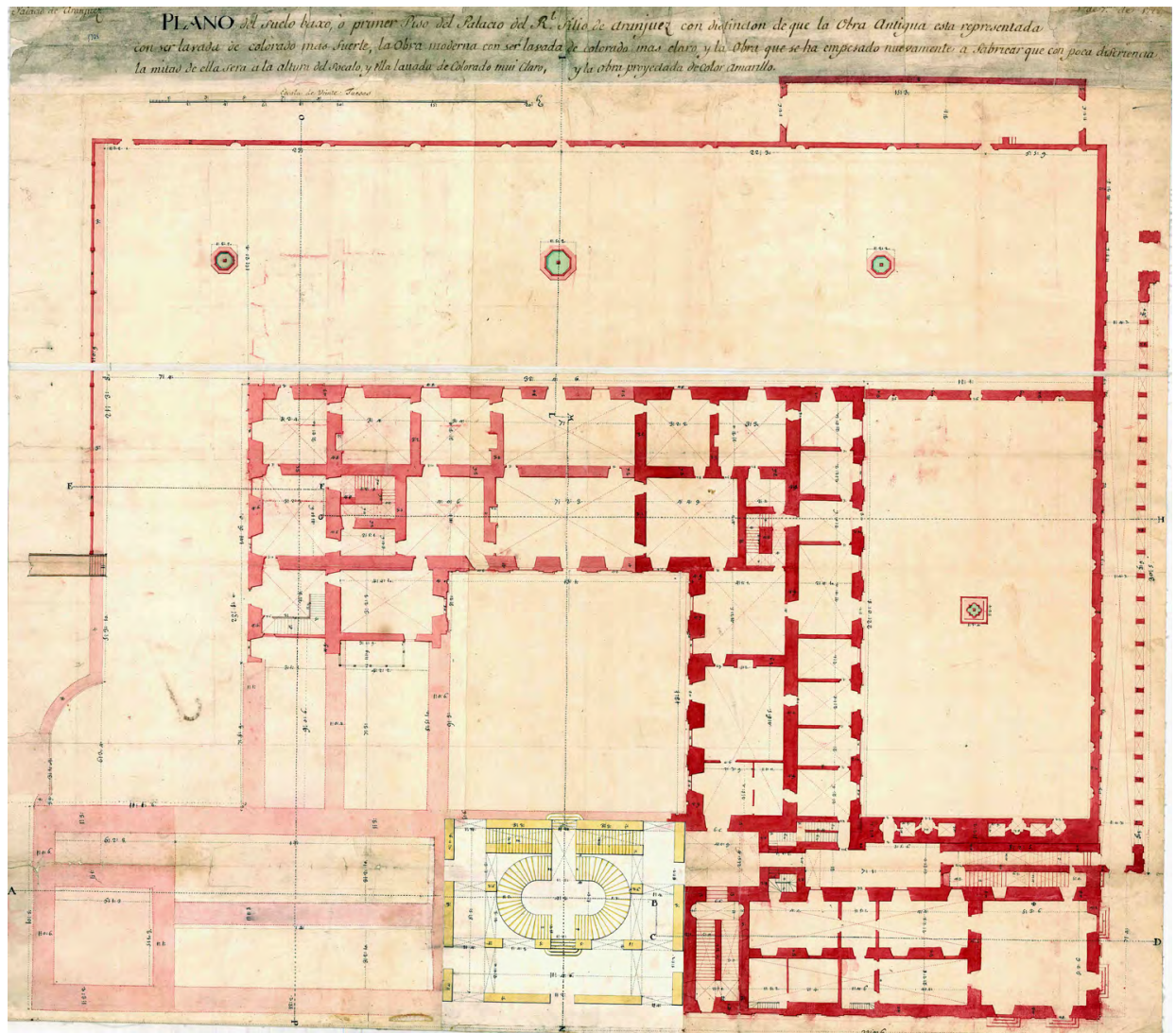

Figura 16. Plano de Pedro Caro Idrogo del palacio de Aranjuez y sus jardines inmediatos, 1728 (Servicio Geográfico del Ejército, n 113-2).

Ediciones Universidad de Salamanca / @®@@ Stud. his., H. ${ }^{a}$ mod., 40, n. 2 (2018), pp. 305-343 